\title{
Strength training and aerobic exercise training for muscle disease (Review)
}

Voet NBM, van der Kooi EL, Riphagen II, Lindeman E, van Engelen BGM, Geurts ACH

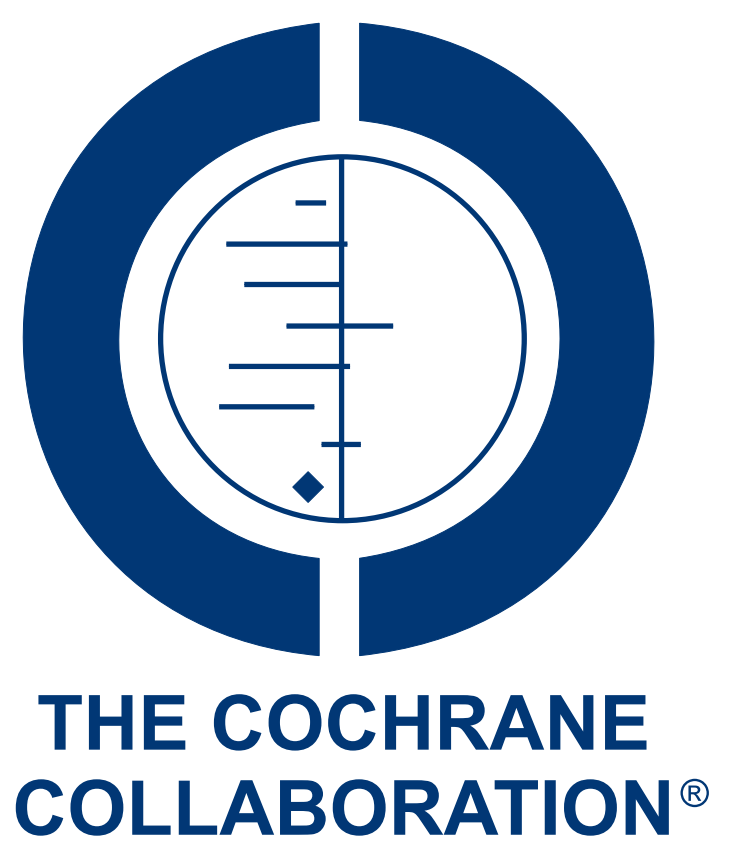

This is a reprint of a Cochrane review, prepared and maintained by The Cochrane Collaboration and published in The Cochrane Library 2011, Issue 7

http://www.thecochranelibrary.com

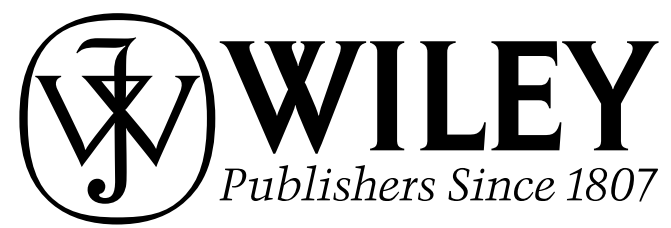

Strength training and aerobic exercise training for muscle disease (Review)

Copyright $\odot$ 20II The Cochrane Collaboration. Published by John Wiley \& Sons, Ltd. 
TABLE OF CONTENTS

HEADER . . . . . . . . . . . . . . . . . . . . . . . . . . . . . . . . . . . . . . . . . . 1

ABSTRACT . . . . . . . . . . . . . . . . . . . . . . . . . . . . . . . . . . . . . . 1

PLAIN LANGUAGE SUMMARY . . . . . . . . . . . . . . . . . . . . . . . . . . . . . . . . . . . . . . $\quad . \quad 2$

BACKGROUND . . . . . . . . . . . . . . . . . . . . . . . . . . . . . . . . . . . . . 2

OBJECTIVES . . . . . . . . . . . . . . . . . . . . . . . . . . . . . . . . . . . . . . . . . . . . . .

METHODS . . . . . . . . . . . . . . . . . . . . . . . . . . . . . . . . . . . . . . 3

RESULTS . . . . . . . . . . . . . . . . . . . . . . . . . . . . . . . . . . . . . . . 5

Figure 1. . . . . . . . . . . . . . . . . . . . . . . . . . . . . . . . . . . . . . 7

Figure 2. . . . . . . . . . . . . . . . . . . . . . . . . . . . . . . . . . . . . . 8

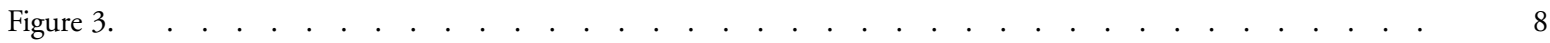

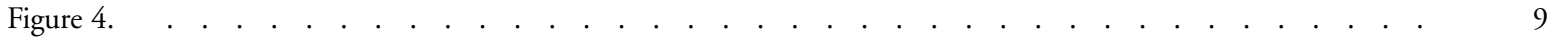

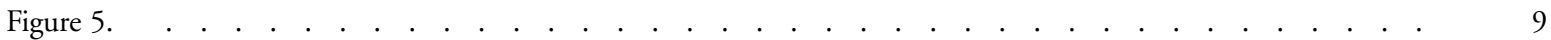

Figure 6. . . . . . . . . . . . . . . . . . . . . . . . . . . . . . . . . . . . . . 9

Figure $7 . \quad$. . . . . . . . . . . . . . . . . . . . . . . . . . . . . . . . . . . . . 10

Figure $8 . \quad$. . . . . . . . . . . . . . . . . . . . . . . . . . . . . . . . . . . . . 10

Figure 9. . . . . . . . . . . . . . . . . . . . . . . . . . . . . . . . . . . . 10

Figure 10. . . . . . . . . . . . . . . . . . . . . . . . . . . . . . . . . . . . . . 11

Figure 11. . . . . . . . . . . . . . . . . . . . . . . . . . . . . . . . . . . . . . 11

Figure 12. . . . . . . . . . . . . . . . . . . . . . . . . . . . . . . . . . . . . . 11

Figure 13. . . . . . . . . . . . . . . . . . . . . . . . . . . . . . . . . . . . . . 12

Figure 14. . . . . . . . . . . . . . . . . . . . . . . . . . . . . . . . . . . . . . 12

DISCUSSION . . . . . . . . . . . . . . . . . . . . . . . . . . . . . . . . . . . . . 13

AUTHORS' CONCLUSIONS . . . . . . . . . . . . . . . . . . . . . . . . . . . . . . . . . . . . . .

ACKNOWLEDGEMENTS . . . . . . . . . . . . . . . . . . . . . . . . . . . . . . . . 16

REFERENCES . . . . . . . . . . . . . . . . . . . . . . . . . . . . . . . . . . . . . 16

CHARACTERISTICS OF STUDIES . . . . . . . . . . . . . . . . . . . . . . . . . . . . . . . . . . 20

DATA AND ANALYSES . . . . . . . . . . . . . . . . . . . . . . . . . . . . . . . . . . . . . . . . . . . . . .

ADDITIONAL TABLES . . . . . . . . . . . . . . . . . . . . . . . . . . . . . . . . . . . . . . . . . . . . 29

WHAT'S NEW . . . . . . . . . . . . . . . . . . . . . . . . . . . . . . . . . . . . . 30

HISTORY . . . . . . . . . . . . . . . . . . . . . . . . . . . . . . . . . . . . . . . 30

CONTRIBUTIONS OF AUTHORS . . . . . . . . . . . . . . . . . . . . . . . . . . . . . . . . . . . . .

DECLARATIONS OF INTEREST . . . . . . . . . . . . . . . . . . . . . . . . . . . . . . . . . . . . 31

DIFFERENCES BETWEEN PROTOCOL AND REVIEW . . . . . . . . . . . . . . . . . . . . . . . 31

INDEX TERMS . . . . . . . . . . . . . . . . . . . . . . . . . . . . . . . . . . . . . . . . 31

Strength training and aerobic exercise training for muscle disease (Review)

Copyright $(201$ I The Cochrane Collaboration. Published by John Wiley \& Sons, Ltd. 


\title{
Strength training and aerobic exercise training for muscle disease
}

\author{
Nicoline BM Voet ${ }^{1}$, Elly L van der Kooi $^{2}$, Ingrid I Riphagen ${ }^{3}$, Eline Lindeman ${ }^{4}$, Baziel GM van Engelen ${ }^{5}$, Alexander CH Geurts ${ }^{6}$ \\ ${ }^{1}$ Department of Rehabilitation, Nijmegen Centre for Evidence Based Practice, Radboud University Nijmegen Medical Center, Ni- \\ jmegen, Netherlands. ${ }^{2}$ Department of Neurology, Medical Centre Leeuwarden, Leeuwarden, Netherlands. ${ }^{3}$ Unit for Applied Clinical \\ Research, Faculty of Medicine, Norwegian University of Science and Technology, Trondheim, Norway. ${ }^{4}$ Rehabilitation Centre Utrecht \\ \& University Medical Centre Utrecht, Utrecht, Netherlands. ${ }^{5}$ Neuromuscular Center Nijmegen, Radboud University Nijmegen Medi- \\ cal Center, Nijmegen, Netherlands. ${ }^{6}$ Department of Rehabilitation, Nijmegen Center for Evidence Based Practice, Radboud University \\ Nijmegen Medical Center, Nijmegen, Netherlands
}

Contact address: Nicoline BM Voet, Department of Rehabilitation, Nijmegen Centre for Evidence Based Practice, Radboud University Nijmegen Medical Center, PO Box 9101, Nijmegen, 6500 HB, Netherlands. N.Voet@reval.umcn.nl.

Editorial group: Cochrane Neuromuscular Disease Group.

Publication status and date: Edited (no change to conclusions), published in Issue 7, 2011.

Review content assessed as up-to-date: 13 July 2009.

Citation: Voet NBM, van der Kooi EL, Riphagen II, Lindeman E, van Engelen BGM, Geurts ACH. Strength training and aerobic exercise training for muscle disease. Cochrane Database of Systematic Reviews 2010, Issue 1. Art. No.: CD003907. DOI: 10.1002/14651858.CD003907.pub3.

Copyright (C) 2011 The Cochrane Collaboration. Published by John Wiley \& Sons, Ltd.

\section{A B S T R A C T}

\section{Background}

Strength training or aerobic exercise programmes might optimise muscle and cardiorespiratory function and prevent additional disuse atrophy and deconditioning in people with a muscle disease.

\section{Objectives}

To examine the safety and efficacy of strength training and aerobic exercise training in people with a muscle disease.

\section{Search methods}

We searched the Cochrane Neuromuscular Disease Group Trials Specialized Register (July 2009), the Cochrane Rehabilitation and Related Therapies Field Register (October 2002, August 2008 and July 2009), The Cochrane Central Register of Controlled Trials (The Cochrane Library Issue 3, 2009) MEDLINE (January 1966 to July 2009), EMBASE (January 1974 to July 2009), EMBASE Classic (1947 to 1973) and CINAHL (January 1982 to July 2009).

\section{Selection criteria}

Randomised or quasi-randomised controlled trials comparing strength training or aerobic exercise programmes, or both, to no training, and lasting at least 10 weeks.

\section{For strength training}

Primary outcome: static or dynamic muscle strength. Secondary: muscle endurance or muscle fatigue, functional assessments, quality of life, muscle membrane permeability, pain and experienced fatigue.

\section{For aerobic exercise training}

Primary outcome: aerobic capacity expressed as work capacity. Secondary: aerobic capacity (oxygen consumption, parameters of cardiac or respiratory function), functional assessments, quality of life, muscle membrane permeability, pain and experienced fatigue. 


\section{Data collection and analysis}

Two authors independently assessed trial quality and extracted the data.

\section{Main results}

We included three trials (121 participants). The first compared the effect of strength training versus no training in 36 people with myotonic dystrophy. The second trial compared strength training versus no training, both combined with albuterol or placebo, in 65 people with facioscapulohumeral muscular dystrophy. The third trial compared combined strength training and aerobic exercise versus no training in 18 people with mitochondrial myopathy. In the myotonic dystrophy trial there were no significant differences between training and non-training groups for primary and secondary outcome measures. In the facioscapulohumeral muscular dystrophy trial only a $+1.17 \mathrm{~kg}$ difference ( $95 \%$ confidence interval 0.18 to 2.16 ) in dynamic strength of elbow flexors in favour of the training group reached statistical significance. In the mitochondrial myopathy trial there were no significant differences in dynamic strength measures between training and non-training groups. Exercise duration and distance cycled in a submaximal endurance test increased significantly in the training group compared to the control group.

\section{Authors' conclusions}

In myotonic dystrophy and facioscapulohumeral muscular dystrophy, moderate-intensity strength training appears not to do harm but there is insufficient evidence to conclude that it offers benefit. In mitochondrial myopathy, aerobic exercise combined with strength training appears to be safe and may be effective in increasing submaximal endurance capacity. Limitations in the design of studies in other muscle diseases prevent more general conclusions in these disorders.

\section{PLAIN LANGUAGESUMMARY}

\section{Strength training or comprehensive aerobic exercise training for muscle disease}

Strength training, which is performed to improve muscle strength and muscle endurance, or aerobic exercise programmes, which involve training at moderate levels of intensity for extended periods of time (for example, distance cycling) might optimise physical fitness and prevent additional muscle wasting in people with muscle disease. However, people with muscle disease and clinicians are still afraid of overuse and have a cautious approach to training. This updated review included two eligible trials on strength training and one new trial on strength training combined with aerobic exercise. These showed that moderate-intensity strength training appears not to harm muscles in people with myotonic dystrophy or with facioscapulohumeral muscular dystrophy, and has a very limited positive effect on muscle strength in facioscapulohumeral muscular dystrophy. Strength training combined with aerobic exercise appears to be safe and may be effective in increasing endurance in people with mitochondrial myopathy. However, there is insufficient evidence for general prescription of exercise programmes in these disorders. More research is needed in all muscle diseases.

\section{B A C K G R O U N D}

When a person is diagnosed as having a muscle disease, questions arise about the prognosis, possible interventions and genetics. However, people with muscle disease are usually also concerned about everyday issues such as participation in sports, work and hobbies. We cannot give evidence-based advice about these issues because we do not know how physical exercise affects the diseased muscular system and the cardiorespiratory system. To answer these questions controlled trials of aerobic exercise and strength training in people with a muscle disease are needed.

Weakness and impaired cardiorespiratory function are common in people with muscle disease. In healthy persons the best intervention to improve strength and cardiorespiratory function is training. Strength training or aerobic exercise programmes in people with muscle disease might maximise muscle and cardiorespiratory function and prevent additional disuse atrophy (Vignos 1983). However, reports of weakness after exercise in people with myopathies have encouraged a cautious approach to training. Therefore, many people with a muscle disease were advised to avoid physical exertion (Brouwer 1992; Fowler 1982; Fowler 1984; Johnson 1971).

The relative rarity of some muscle diseases has led many researchers 
to group participants with different neuromuscular disorders together, including myopathies, neuropathies and motor neuron disease (Aitkens 1993; Dawes 2006; Kilmer 1994; Kilmer 2005; McCartney 1988; Milner-Brown 1988a; Milner-Brown 1988b; Wright 1996). As the pathophysiology of these disorders differs, their reaction to an intervention might be different. Therefore, conclusions about the effect of training derived from these mixed populations cannot readily be extrapolated to people with specific muscular disorders (Lindeman 1995).

The benefit from strength training or aerobic exercise training in muscle diseases is still not clear (Kilmer 1998), therefore in this update we systematically reviewed controlled trials of these interventions for people with specified muscle diseases.

\section{O B J E C T IVES}

The objective was to systematically review the evidence from randomised controlled trials concerning the efficacy and safety of strength training and aerobic exercise training in people with muscle disease.

\section{METHODS}

\section{Criteria for considering studies for this review}

\section{Types of studies}

We included all randomised or quasi-randomised controlled trials that made any of the following comparisons:

- strength training versus no training;

- aerobic exercise training versus no training;

- combined strength training and aerobic exercise versus no training.

\section{Types of participants}

We selected all trials including participants with a well-described diagnosis of a muscle disease, such as inflammatory myopathies, metabolic myopathies, muscular dystrophies, muscle diseases with myotonia and other well-defined myopathies. We decided not to include studies looking at strength training or aerobic exercise training for people in whom muscle weakness was not the primary feature, but might have been secondary to chronic renal insufficiency, chronic heart failure, renal or heart transplantation, or corticosteroid use. We did not review the effects of respiratory muscle training.

\section{Types of interventions}

We included all forms of strength training and aerobic exercise training lasting at least 10 weeks.

\section{Definitions}

- Training, or physical fitness training: a planned, structured regimen of regular physical exercise deliberately performed to improve one or more of the following components of physical fitness: cardiorespiratory fitness, body composition, muscle strength and endurance, and flexibility (Pollock 1998; USDHHS 1996).

- Strength training: training performed primarily to improve muscle strength and endurance. It is typically carried out making repeated muscle contractions against resistance (Saunders 2004).

- Aerobic exercise training, or cardiorespiratory fitness training: training that consists of an activity or combination of activities that uses large muscle groups, that can be maintained continuously, and that is rhythmical and aerobic in nature, for example walking-hiking, running-jogging, cycling-bicycling, aerobic dance exercise or swimming (Pollock 1998).

\section{Types of outcome measures}

\section{Primary outcomes}

The primary outcome measure for strength training was:

- muscle strength, expressed in measures of static (i.e. isometric) or dynamic strength.

The secondary outcome measure specific to strength training was: - muscle endurance or muscle fatigue.

The primary outcome measure for aerobic exercise training was: - aerobic capacity, expressed in measures of work capacity.

The secondary outcome measure specific to aerobic exercise training was:

- aerobic capacity, expressed in measures of oxygen consumption, parameters of cardiac function or parameters of respiratory function.

\section{Secondary outcomes}

Secondary outcome measures applicable to both strength training and aerobic exercise training were:

- timed-scored functional assessments of muscle performance;

- quality of life;

- parameters of muscle membrane permeability (serum creatine kinase level, myoglobin level) to assess the safety;

- experienced pain;

- experienced fatigue. 
We compared data on outcome measures at baseline with those obtained after at least 10 weeks of training. When there were assessments at more than one time (during the intervention, after cessation of the intervention), our preference was for data on outcome measures obtained at the end of the intervention.

\section{Search methods for identification of studies}

We searched the Cochrane Neuromuscular Disease Group Trials Specialized Register for randomised trials (14 July 2009) using the following search terms: "muscle dis*" or "muscle weakness" or "muscular dis*" or "neuromuscular dis*" or "myopath" or "dystroph*" or "myotoni*" or "myositis" or "polio*" or "muscle fibre*" or "muscle strength" and "exercise therapy" or "exercise training" or "exercise program*" or "strength training" or "aerobic training" or "aerobic exercise" or "training program" or "resistive exercise" or "endurance training" or "muscle exercise".

One of the authors (IIR) designed and ran similar search strategies in The Cochrane Central Register of Controlled Trials (The Cochrane Library Issue 3, 2009), MEDLINE (January 1966 to July 2009), EMBASE (January 1974 to July 2009), EMBASE Classic (1947 to 1973) and CINAHL (January 1982 to July 2009). The Cochrane Rehabilitation and Related Therapies Field helped to search the literature in the rehabilitation and physical therapy field (database and handsearched material) (August 2008). We reviewed the bibliographies of the trials identified and other reviews covering the subject, and contacted some of the authors in the field to identify additional published and unpublished data. As the search methods used in this updated review have not been changed, we also included studies from the previous version of this review.

\section{Data collection and analysis}

\section{Selection of studies}

Two authors (Voet, van der Kooi) checked the references identified by the search strategy. The full text of all potentially relevant studies was obtained for independent assessment by both authors. We decided which trials fitted the inclusion criteria.

\section{Data extraction and management}

We independently extracted the data from the included trials onto a specially designed data extraction form, and graded the methodological quality and certain other aspects of the design of the included trials.

\section{Assessment of risk of bias in included studies}

Aspects of trial design that we assessed were as follows. A. Diagnostic criteria. We used the Diagnostic Criteria for Neuromuscular Disorders as defined by the European Neuromuscular Centre (ENMC) as a guide (Emery 1997).

B. Design of the training programme - because there are no evidence based prescriptions of exercise programmes for people with a muscle disease, we used the recommendations from the American College of Sports Medicine (ACSM) Position Stand on 'The Recommended Quantity and Quality of Exercise for Developing and Maintaining Cardiorespiratory and Muscular Fitness, and Flexibility in Healthy Adults' as minimal requirements to evaluate the quality of the training programmes (Pollock 1998).

- For effective strength training the ACSM recommendations are that it should be an individualised programme, which is progressive in nature, and which provides a stimulus to all the major muscle groups. At least one set of eight to ten exercises should condition the major muscle groups two to three days per week. Most persons should complete eight to 12 repetitions of each exercise but older or frail persons should do 10 to 15 repetitions with lower resistance. In addition, we required that the type of strength training exercise, i.e. static (isometric) or dynamic (concentric, excentric, isokinetic) should be indicated. We also required that the duration of an exercise session should not exceed 60 minutes, in order not to interfere too much with other daily activities. The load required to increase maximal strength in untrained individuals is fairly low. Loads of $45 \%$ to $50 \%$ of the one repetition maximum (1RM), and less, have been shown to increase dynamic muscular strength in previously untrained individuals (Kraemer 2002).

- For aerobic exercise training the ACSM states that the mode of activity can be any activity that uses large muscle groups, which can be maintained continuously, and is rhythmic and aerobic in nature. The optimal frequency of training is three to five days per week. Intensity of training should be at $55 \%$ to $90 \%$ of maximum heart rate, or $40 \%$ to $85 \%$ of maximum oxygen uptake reserve or maximum heart rate reserve. The duration of training should be 20 to 60 minutes continuously or intermittently in bouts of at least 10 minutes.

- Based on what is known from adaptations of strength training in healthy individuals, we decided that the entire programme duration should be at least 10 weeks to be able to detect training effects based on both neural adaptation (which has its maximum contribution in first four to six weeks) and muscle hypertrophy (which has its main contribution after six weeks).

- The type of exercise supervision was also evaluated, because the regular supervision of training improves the effect and safety of exercise, and the compliance of the participants.

We described and ranked the following qualities of the training programmes: type of exercise training, intensity, frequency, dura- 
tion per exercise session, duration of the entire programme, (number of) trained muscle groups, supervision of training.

C. Methodological quality - we assessed risk of bias and other aspects according to the Cochrane approach using the updated guidance in the Cochrane Handbook for Systematic Reviews of Interventions (Higgins 2008). We assessed the included studies for randomisation sequence generation, allocation concealment, blinding (participants and outcome assessors), incomplete outcome data, selective outcome reporting and other sources of bias. When there was uncertainty, authors were contacted for clarification. We resolved disagreement about fulfilment of inclusion or quality criteria by discussion between the two authors. We made a judgement on each of these criteria relating to the risk of bias, such that a judgement of 'yes' indicated a low risk of bias, 'no' a high risk of bias and 'unclear' an unclear or unknown risk of bias. Whenever characteristics of study design or drop-out rates were likely to cause a higher risk of bias, this would be noted and the possibility of differences in treatment effects varying with the degree of this problem would be investigated.

\section{Data synthesis}

We intended to combine trial results for appropriate pairings of treatments by calculating a weighted mean of the difference between their effects using the Cochrane statistical package Review Manager 5.0 (RevMan) (RevMan 2008). Because pooling of the results of trials on different muscle diseases is usually not appropriate, we expressed, when possible, the results per muscle disease as mean differences (WMD) with $95 \%$ confidence intervals (95\% CI) for continuous outcomes, and risk ratios (RR) with 95\% CI for dichotomous outcome measures. The intended testing for heterogeneity, and consequent actions, turned out to be unnecessary.

\section{Subgroup analysis and investigation of heterogeneity}

We decided, in advance, not to perform subgroup analyses based on sex or age because we anticipated that the differences in muscle disease severity would have a much bigger influence on outcome than sex or age. Moreover, the American College of Sports Medicine stated in their Position Stand (Pollock 1998) that relative improvements resulting from aerobic and strength training are similar for young and old, male and female.

\section{RE S U L T S}

\section{Description of studies}

See: Characteristics of included studies; Characteristics of excluded studies.
In this update, following further screening, we identified 24 completed trials (19 in the original review) that studied strength training as an intervention, 18 trials studying aerobic exercise training (nine in the original review), and 11 trials studying combined strength training and aerobic exercise (eight in the original review), sometimes incorporated in more comprehensive rehabilitation programmes. Most strength training trials included people with the following muscle diseases: slowly progressive dystrophies (mostly myotonic dystrophy, limb-girdle dystrophies, facioscapulohumeral muscular dystrophy), and in the older studies nonspecified progressive muscular dystrophies and inflammatory myopathies. Studies on the effects of aerobic exercise training included mainly people with slowly progressive dystrophies and metabolic myopathies (mostly unspecified mitochondrial myopathies).

Studies have generally been limited by small sample sizes. We excluded 44 trials because there was no randomised controlled comparison between training and non-training patients (see Characteristics of excluded studies). Six studies randomly assigned one limb to be exercised, with the contralateral non-exercised side serving as the control limb (Aitkens 1993; De Lateur 1979; Kilmer 1994; McCartney 1988; Milner-Brown 1988b; Tollbäck 1999). In all these six studies, strength gains in the exercised limb were the same or only slightly greater than in the non-exercised limb. In the resistance exercise trial of Aitkens, for example, strength gains did not significantly differ between the exercised and non-exercised limbs in either group (Aitkens 1993). This concept is called crosseducation, and has been described with different forms of exercises. A meta-analysis of 16 randomised studies concluded that, on average, the magnitude of cross-education is $8 \%$ of the initial strength of the untrained limb (Munn 2004). Neural adaptations to training and learning effects due to testing are postulated as explanations (Lee 2007; Munn 2005; Sale 1988; Shima 2002). Moreover, the results may well be confounded by the presence of asymmetric weakness of both limbs, as the absolute gain in muscle strength resulting from strength training is related to pre-exercise muscle weakness (Kilmer 2002). Therefore, a non-exercised limb is not an appropriate control, even if training was randomly assigned. For this reason, we have excluded studies using a withinsubjects design. We will revise the protocol to a priori exclude these studies in the next update.

The majority of the studies did not have a non-training control group of patients, or used a healthy control group. Only five studies (three in the original review) were randomised controlled trials making a comparison between training and non-training patients. Regrettably, the extension of the initially randomised controlled six-week aerobic exercise study in people with polymyositis and dermatomyositis by Wiesinger et al lost its randomised controlled design due to a decision of the ethics committee. We had to exclude the first part of this study (Wiesinger 1998a) as it did not meet our predefined criterion that the training programme should be at least 10 weeks long, and the second part (Wiesinger 1998b) as it was no longer randomised controlled. randomised controlled trial 
on the effect of combined strength training and aerobic exercise in a group of participants with different muscle diseases in this update due to the training duration of only eight weeks (Dawes 2006).

In conclusion, two strength training trials and one strength training combined with aerobic exercise trial, newly identified in this update, met all the inclusion criteria. The first strength training trial compared the effect of 24 weeks of training versus no training in 36 adults with myotonic dystrophy and 30 adults with hereditary motor and sensory neuropathy (Lindeman 1995). As this review is concerned with muscle disease, we will not discuss the results of the hereditary motor and sensory neuropathy patient group. The second strength training trial compared 52 weeks of strength training versus no training, both combined with albuterol or placebo as add-on after the first 26 weeks of training in 65 adult participants with facioscapulohumeral muscular dystrophy (van der Kooi 2004). The trial which combined aerobic exercise and strength training compared 12 weeks of cycle exercises and dynamic and isokinetic strength training in 18 people with mitochondrial myopathy (Cejudo 2005) (see Characteristics of included studies) .

\section{Risk of bias in included studies}

In the myotonic dystrophy trial (Lindeman 1995) participants with myotonic dystrophy were individually matched for muscle strength and performance in a stair-climbing test. Within each matched pair, participants were randomly assigned to the training or control group. There was no published information on the method of randomisation or on allocation concealment but the first author (Lindeman) informed us that two independent persons drew one sealed name per matched pair and allocated it by tossing a coin to the training or non-training group. We graded the intention to blind the clinical evaluators as adequate although approximately $20 \%$ of the myotonic dystrophy participants revealed information to the clinical evaluators that resulted in unblinding during the course of the trial. Baseline data for both experimental groups were presented. The authors considered the comparability as suboptimal because the training group contained more women, was somewhat older, had longer time scores for stair climbing (a measure of functional ability) and had higher knee torques (a measure of muscle strength). They argued that the first three items could have resulted in an underestimation of the training effect, whereas the last item could have resulted in an overestimation of the training effect. They concluded that the differences in experimental group composition did not seem to explain the absence of differences in outcomes between treatment groups. We considered the way the authors presented and discussed the baseline differences as adequate. Three of the initially 36 randomised participants withdrew before disclosure of treatment allocation. The 33 participants starting the trial made 15 matched pairs. During the trial one person dropped out. Because of the matched pair design only complete pairs were analysed, thus eventually 28 of the initial 36 randomised participants were analysed. Follow up was thus incomplete and analysis was not by 'intention-to-treat'. However, the flow path of participants was well documented. In the facioscapulohumeral muscular dystrophy trial (van der Kooi 2004) 65 participants were stratified into two groups based on muscle strength. Participants in both strata were randomly assigned to one of the four treatment groups according to a computer generated randomisation list. The treatments consisted of training plus albuterol, training plus placebo, non-training plus albuterol, or non-training plus placebo. Training or non-training was the first intervention, starting just after the baseline visit until after the final visit at 52 weeks. After 26 weeks participants started using the blinded trial medication. Information on the assignment to training or non-training was disclosed to the participants by the physical therapist (supervising the training programme) after their baseline visit. Participants received the blinded trial medication from the pharmacy department. The clinical evaluator was blinded for the assignment to both interventions. The participants, physical therapist and the neurologist evaluating the side effects were blinded to the study medication. The blinding of the clinical evaluator was considered adequate, although one of the main secondary outcome measures, the one repetition maximum (1RM) measurement for assessing dynamic strength, was performed by the physical therapist who supervised the training, and who was therefore not blinded to the allocation to training or non-training. Allocation to the training or non-training group was unmasked in three cases, due to unintentional remarks. The success of blinding for the study medication was not formally checked. Baseline characteristics were presented for all treatment groups. One participant stopped training and four participants stopped using their study medication, but they still attended all trial visits, resulting in complete follow up of all participants. Data analysis was by intention-to-treat principle. As no statistically significant interactions between the two interventions (i.e. training versus non-training; albuterol versus placebo) could be detected, the effect sizes, being the differences in mean change from baseline, were presented for each intervention.

In the mitochondrial myopathy trial (Cejudo 2005), 20 participants were randomly assigned to the training or control group. There was no published information on the method of randomisation, allocation concealment, or blinding of the evaluators. The author (Cejudo) informed us that participants were randomly assigned according to a computer generated randomisation list. The evaluators were not blinded to the intervention allocation but knew to which group each participant was assigned. One participant in each group failed to finish the study for personal reasons. Baseline assessment data were available for these participants, but not published. Follow up was therefore incomplete and analysis was not done by 'intention-to-treat'. No flow path of participants was documented. Baseline characteristics were presented for both groups, except for the participants lost to follow up. The authors 
considered both groups as comparable with respect to anthropometric features, as well as to each measured variable at baseline. Each criterion was ranked using the Cochrane approach. The review authors' judgements about each methodological quality item for included studies are presented in Figure 1.

Figure I. Methodological quality summary: review authors' judgements about each methodological quality item for each included study.

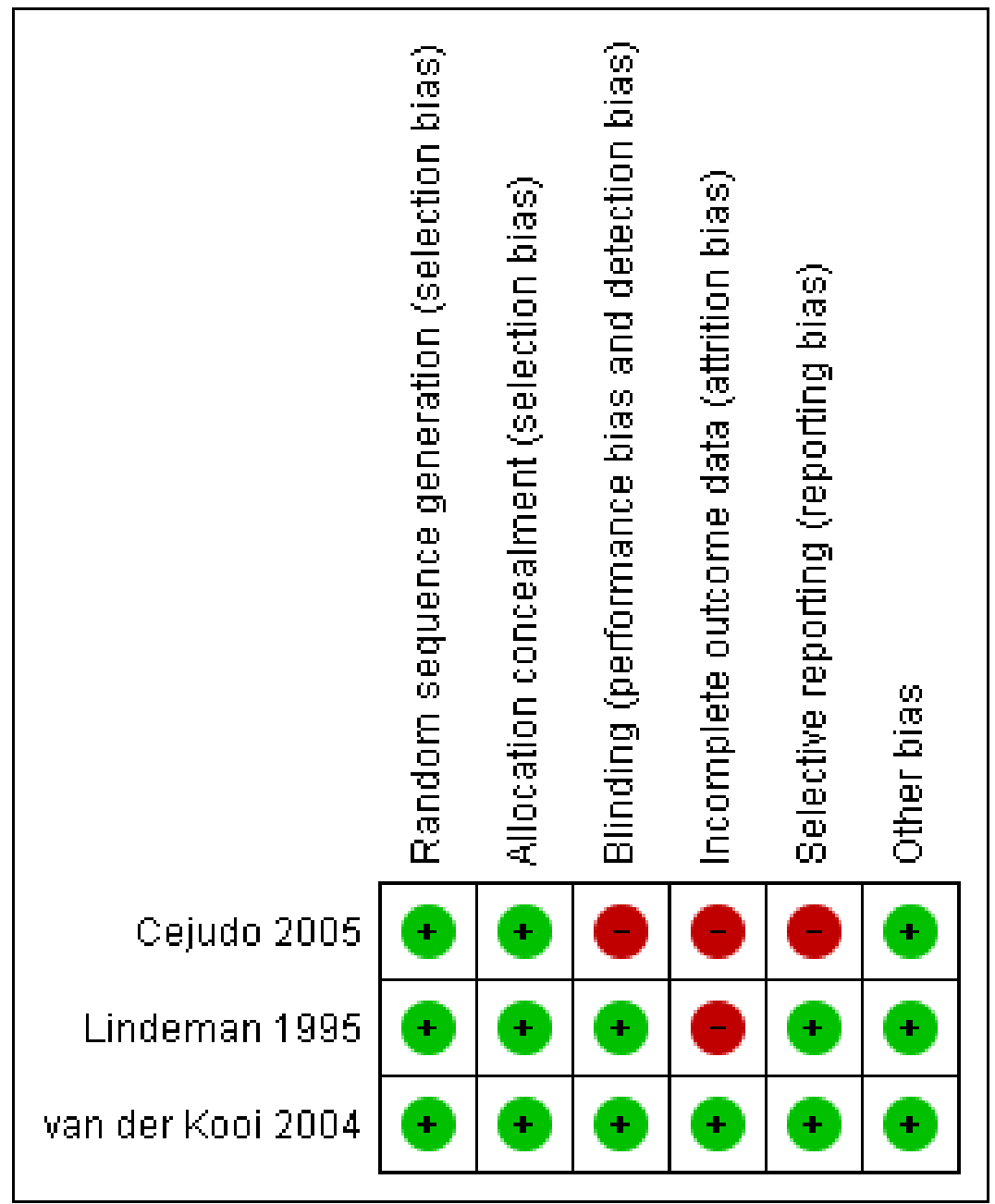

\section{Quality diagnostic criteria}

This quality assessment took into account if and how diagnoses were verified. In the myotonic dystrophy trial participants were recruited via neurologists, physiatrists and the Dutch association for neuromuscular diseases (Vereniging Spierziekten Nederland) on clinical grounds and without genetic verification. We therefore graded the quality of the diagnostic criteria as inadequate. In the facioscapulohumeral muscular dystrophy trial either participants, or a first-degree relative, had the associated deletion at chromosome 4 (Deidda 1996). The quality of the diagnosis was therefore 
graded as adequate. In the mitochondrial myopathy trial participants were recruited from a larger group of patients followed at the university hospital of Sevilla, Spain. Diagnosis was based on clinical and muscle biopsy data. Biopsy findings were determined by biochemical and histological techniques without genetic verification. One participant in each group only had a probable diagnosis of mitochondrial myopathy. We graded the quality of the diagnostic criteria as uncertain.

\section{Quality training programme}

The training programmes of the myotonic dystrophy, facioscapulohumeral muscular dystrophy and mitochondrial myopathy trials fulfilled most of the minimal requirements as defined in the Methods section. The training scheme for all trials was inadequate only with respect to the number of muscle groups trained, as the ACSM recommends eight to 10 exercises of all the major muscle groups. Only four muscle groups were trained in the myotonic dystrophy trial, two in the facioscapulohumeral muscular dystrophy trial and three in the mitochondrial myopathy trial. All studies focused on a limited number of muscle groups for reasons of effect evaluation, safety and time restraints per training session. A description of the training programmes and their scores are listed in Table 1.

\section{Effects of interventions}

We intended to combine trial results for appropriate pairings of treatments by calculating a weighted mean of the difference between their effects using the Cochrane statistical package RevMan. Because we could not obtain the original data for the mitochondrial myopathy trial, we will describe the results of this trial as published in the article.

\section{Primary outcome measure for strength training: muscle strength - expressed in measures of static (i.e. isometric) or dynamic strength}

Muscle strength was the primary outcome measure for the myotonic dystrophy and facioscapulohumeral muscular dystrophy trials. In the myotonic dystrophy trial (Lindeman 1995) differences in muscle strength were measured isokinetically as maximum concentric knee torques at three velocities, and isometrically as maximum voluntary contraction. Mean differences between groups were $3.90 \mathrm{Nm}$ (95\% CI -4.11 to 11.91) for isokinetic knee torque extension (Figure 2), $3.70 \mathrm{Nm}$ (95\% CI -3.78 to 11.18) for isokinetic knee torque flexion (Figure 3) and $2.10 \mathrm{Nm}(95 \%$ CI -7.52 to 11.72) for maximum isometric voluntary contraction (Figure 4), all in favour of the training group, although insignificant.

Figure 2. Forest plot of comparison: I Strength training versus control in Myotonic Dystrophy, outcome: I.I Muscle strength - maximum isotonic knee torque extension.

\begin{tabular}{|c|c|c|c|c|c|c|c|c|c|}
\hline \multirow[b]{2}{*}{ Study or Subgroup } & \multicolumn{3}{|c|}{ Training } & \multicolumn{3}{|c|}{ Control } & \multicolumn{2}{|r|}{ Mean Difference } & \multirow{2}{*}{$\begin{array}{l}\text { Mean Difference } \\
\text { N, Fixed, 95\% CI }\end{array}$} \\
\hline & Mean & SD & Total & Mean & SD & Total & Weight & N, Fixed, $95 \% \mathrm{Cl}$ & \\
\hline Lindeman 1995 & 5.3 & 12.9 & 14 & 1.4 & 8.2 & 14 & $100.0 \%$ & $3.90[-4.11,11.91]$ & \\
\hline Total $(95 \%$ Cl) & & & 14 & & & 14 & $100.0 \%$ & $3.90[-4.11,11.91]$ & \\
\hline $\begin{array}{l}\text { Heterogeneity: Not a } \\
\text { Test for overall effec }\end{array}$ & $\begin{array}{l}\text { plicable } \\
Z=0.95\end{array}$ & $(P=0$ & & & & & & & $\begin{array}{cccc}-10 & -5 & 0 & 5 \\
& \text { Control Trainin }\end{array}$ \\
\hline
\end{tabular}

Figure 3. Forest plot of comparison: I Strength training versus control in Myotonic Dystrophy, outcome: I.2 Muscle strength - maximum isotonic knee torque flexion.

\begin{tabular}{|c|c|c|c|c|c|c|c|c|c|}
\hline \multirow[b]{2}{*}{ Study or Subgroup } & \multicolumn{3}{|c|}{ Training } & \multicolumn{3}{|c|}{ Control } & \multirow[b]{2}{*}{ Weight } & Mean Difference & \multirow{2}{*}{$\begin{array}{l}\text { Mean Difference } \\
\text { N, Fixed, 95\% } \mathrm{Cl}\end{array}$} \\
\hline & Mean & SD & Total & Mean & SD & Total & & N, Fixed, 95\% Cl & \\
\hline Lindeman 1995 & 7.4 & 11.4 & 14 & 3.7 & 8.6 & 14 & $100.0 \%$ & $3.70[-3.78,11.18]$ & \\
\hline Total (95\% Cl) & & & 14 & & & 14 & $100.0 \%$ & $3.70[-3.78,11.18]$ & \\
\hline \multicolumn{7}{|c|}{ Test for overall effect: $Z=0.97(P=0.33)$} & & & $\begin{array}{cccc}-10 & -5 & 0 & 5 \\
& \text { Control Training }\end{array}$ \\
\hline
\end{tabular}


Figure 4. Forest plot of comparison: I Strength training versus control in Myotonic Dystrophy, outcome: I.3 Muscle strength - maximum isometric voluntary contraction.

\begin{tabular}{|c|c|c|c|c|c|c|c|c|c|c|}
\hline \multirow[b]{2}{*}{ Stucty or Subgroup } & \multicolumn{3}{|c|}{ Training } & \multicolumn{3}{|c|}{ Control } & \multirow[b]{2}{*}{ Weight } & \multicolumn{2}{|l|}{ Mean Difference } & \multirow{2}{*}{$\begin{array}{l}\text { Mean Difference } \\
\text { N, Fixed, 95\% Cl }\end{array}$} \\
\hline & Mean & SD & Total & Mean & SD & Total & & N, Fixed, 95\% Cl & & \\
\hline Lindeman 1995 & 8.7 & 14.7 & 14 & 6.6 & 11 & 14 & $100.0 \%$ & $2.10[-7.52,11.72]$ & & \\
\hline Total $(95 \% \mathrm{Cl})$ & & & 14 & & & 14 & $100.0 \%$ & $2.10[-7.52,11.72]$ & & \\
\hline \multicolumn{11}{|c|}{ 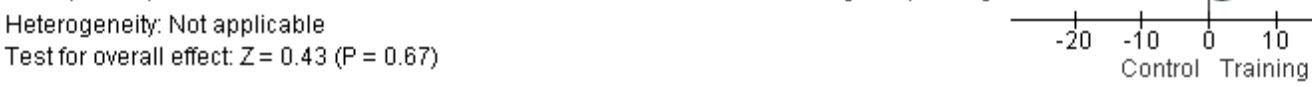 } \\
\hline
\end{tabular}

The primary outcome measure in the facioscapulohumeral muscular dystrophy trial (van der Kooi 2004) was a change in maximum voluntary isometric strength of the elbow flexors and ankle dorsiflexors. After 52 weeks the isometric strength of the elbow flexors did not differ significantly between the training and nontraining group (mean difference right side $0.54 \mathrm{kgF}, 95 \% \mathrm{CI}-0.38$ to 1.46 , with the better score being for the training group, Figure 5). Dynamic strength was evaluated using the one repetition maximum (1RM), the weight a person can lift once, but not twice, at a steady controlled pace through the full range of joint motion. The $1 \mathrm{RM}$ showed a significantly larger increase in the training group compared to the non-training group (mean difference right side $1.20 \mathrm{~kg}, 95 \%$ CI 0.18 to 2.16 , Figure 6). Both strength measures of the ankle dorsiflexors decreased significantly and markedly in all treatment groups. This decrease was not influenced by training (on the right side mean difference in maximum voluntary isometric contraction (MVIC) $0.43 \mathrm{kgF}, 95 \% \mathrm{CI}-1.62$ to 2.48 , more for the training group (Figure 7 ), in $1 \mathrm{RM}-0.44 \mathrm{~kg}, 95 \% \mathrm{CI}-1.77$ to 0.89 , less for the training group (Figure 8 ). Changes in strength measures for the left-sided trained muscle groups did not differ significantly from the right-sided results.

Figure 5. Forest plot of comparison: 2 Strength training versus control in FSHD, outcome: 2 .I Muscle strength elbow flexors - maximum voluntary isometric contraction.

\begin{tabular}{|c|c|c|c|c|c|c|c|c|c|}
\hline \multirow[b]{2}{*}{ Study or Subgroup } & \multicolumn{3}{|c|}{ Training } & \multicolumn{3}{|c|}{ Control } & \multicolumn{2}{|r|}{ Mean Difference } & \multirow{2}{*}{$\begin{array}{l}\text { Mean Difference } \\
\text { N, Fixed, 95\% CI }\end{array}$} \\
\hline & Hean & SD & Total & Mean & SD & Total & Weight & N, Fixed, 95知 Cl & \\
\hline van der Kooi 2004 & -0.06 & 1.93 & 34 & -0.6 & 1.87 & 31 & $100.0 \%$ & $0.54[-0.38,1.46]$ & \\
\hline Total (95\% Cl) & & & 34 & & & 31 & $100.0 \%$ & $0.54[-0.38,1.46]$ & \\
\hline \multicolumn{9}{|c|}{$\begin{array}{l}\text { Heterogeneity: Not applicable } \\
\text { Test for overall effect: } Z=1.15(P=0.25)\end{array}$} & $\begin{array}{cccc} & 1 & 1 & 1 \\
-4 & -2 & 0 & 2 \\
& \text { Control } & \\
& \text { Training }\end{array}$ \\
\hline
\end{tabular}

Figure 6. Forest plot of comparison: 2 Strength training versus control in FSHD, outcome: 2.2 Muscle strength elbow flexors - dynamic strength.

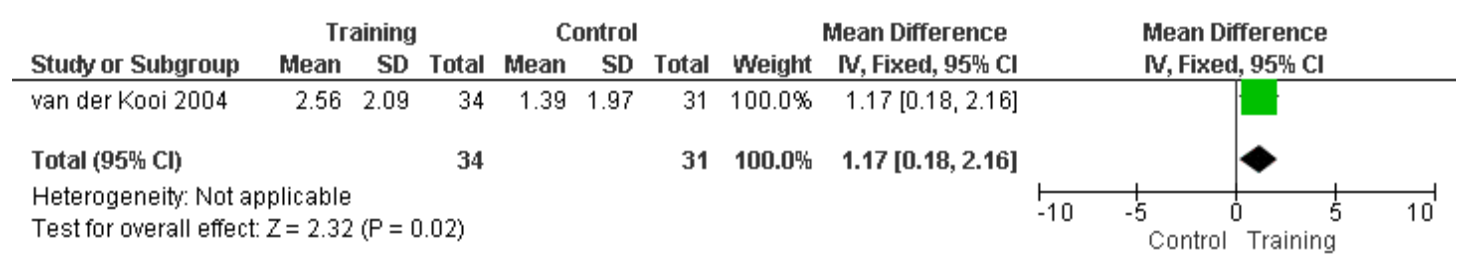


Figure 7. Forest plot of comparison: 2 Strength training versus control in FSHD, outcome: 2.3 Muscle strength ankle dorsiflexors - maximum isometric voluntary contraction.

\begin{tabular}{|c|c|c|c|c|c|c|c|c|c|c|c|}
\hline \multirow[b]{2}{*}{ Study or Subgroup } & \multicolumn{3}{|c|}{ Treatment } & \multicolumn{3}{|c|}{ Control } & \multicolumn{3}{|c|}{ Mean Difference } & \multirow{2}{*}{$\begin{array}{l}\text { Mean Difference } \\
\text { N, Fixed, 95\% Cl }\end{array}$} & \\
\hline & Mean & SD & Total & Mean & SD & Total & Weight & N, Fixed, 95咜 Cl & & & \\
\hline van der Kooi 2004 & -1.13 & 4.28 & 34 & -1.56 & 4.16 & 31 & $100.0 \%$ & $0.43[-1.62,2.48]$ & & & \\
\hline Total (95\% Cl) & & & 34 & & & 31 & $100.0 \%$ & $0.43[-1.62,2.48]$ & & & \\
\hline $\begin{array}{l}\text { Heterogeneity: Not a } \\
\text { Test for overall effect }\end{array}$ & $\begin{array}{l}\text { plicable } \\
Z=0.41\end{array}$ & & 1.68) & & & & & & $\stackrel{!}{-10}$ & $\begin{array}{ccc}-5 & 0 & 5 \\
& & \\
& & \\
& & \end{array}$ & 10 \\
\hline
\end{tabular}

Figure 8. Forest plot of comparison: 2 Strength training versus control in FSHD, outcome: 2.4 Muscle strength ankle dorsiflexors - dynamic strength.

\begin{tabular}{|c|c|c|c|c|c|c|c|c|c|c|c|}
\hline \multirow[b]{2}{*}{ Stucty or Subgroup } & \multicolumn{3}{|c|}{ Treatment } & \multicolumn{3}{|c|}{ Control } & \multicolumn{3}{|c|}{ Mean Difference } & \multirow{2}{*}{$\begin{array}{l}\text { Mean Difference } \\
\text { N, Fixed, 95\% Cl }\end{array}$} & \\
\hline & Mean & SD & Total & Mean & SD & Total & Weight & N, Fixed, 95\% Cl & & & \\
\hline van der Kooi 2004 & -1.5 & 2.68 & 34 & -1.06 & 2.78 & 31 & $100.0 \%$ & $-0.44[-1.77,0.89]$ & & & \\
\hline Total $(95 \% \mathrm{Cl})$ & & & 34 & & & 31 & $100.0 \%$ & $-0.44[-1.77,0.89]$ & & & \\
\hline $\begin{array}{l}\text { Heterogeneity: Not a } \\
\text { Test for overall effect }\end{array}$ & $\begin{array}{l}\text { plicable } \\
Z=0.65\end{array}$ & & & & & & & & -10 & $\begin{array}{lll}-5 & 0 & 5 \\
& & \\
& \text { Control Training }\end{array}$ & 10 \\
\hline
\end{tabular}

Muscle strength was a secondary outcome for the mitochondrial myopathy trial (Cejudo 2005). Weight-lifting capacity was measured as the heaviest weight that could be lifted throughout the complete range of movement (1RM test). After the study period, all participants showed increases in all $1 \mathrm{RM}$ tests. After 12 weeks weight-lifting capacity did not differ significantly between the training and non-training group. Mean differences in 1RM between groups were $-5.00 \mathrm{~kg}$ (95\% CI -14.71 to 4.71$)$ for the shoulder press exercise (Figure 9), $6.40 \mathrm{~kg}$ (95\% CI -2.89 to 15.69) for the butterfly exercise (Figure 10) and $7.30 \mathrm{~kg}$ (95\% CI -2.91 to 17.51) for the biceps curls exercise (Figure 11).

Figure 9. Forest plot of comparison: 5 Aerobic exercise and strength training in mitochondrial myopathy, outcome: 5.I Muscle strength shoulder press - maximum dynamic isotonic voluntary contraction.

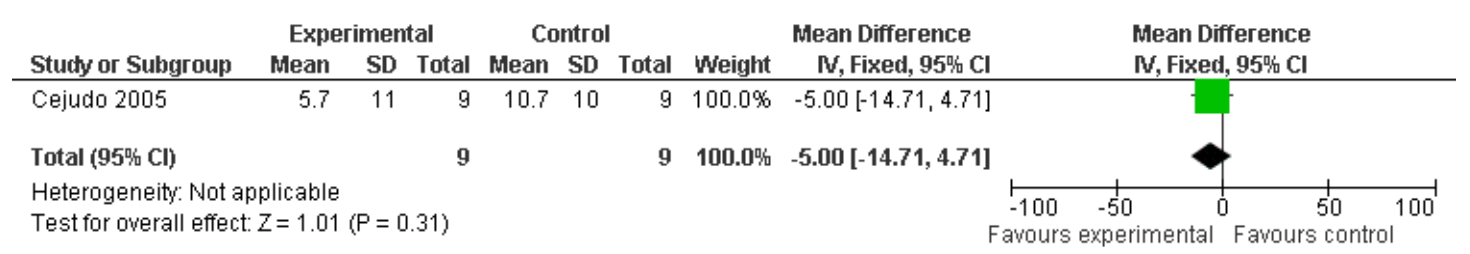


Figure 10. Forest plot of comparison: 5 Aerobic exercise and strength training in mitochondrial myopathy, outcome: 5.2 Muscle strength butterfly - maximum dynamic isotonic voluntary contraction.

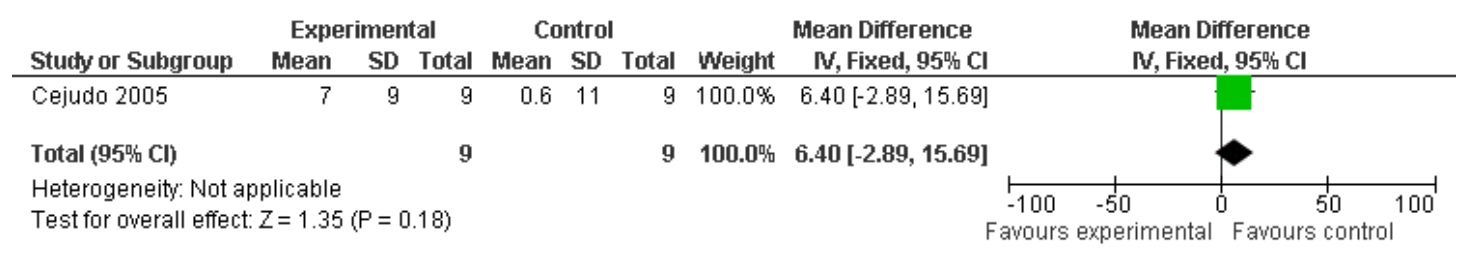

Figure I I. Forest plot of comparison: 5 Aerobic exercise and strength training in mitochondrial myopathy, outcome: 5.3 Muscle strength biceps curls - maximum isotonic dynamic voluntary contraction .

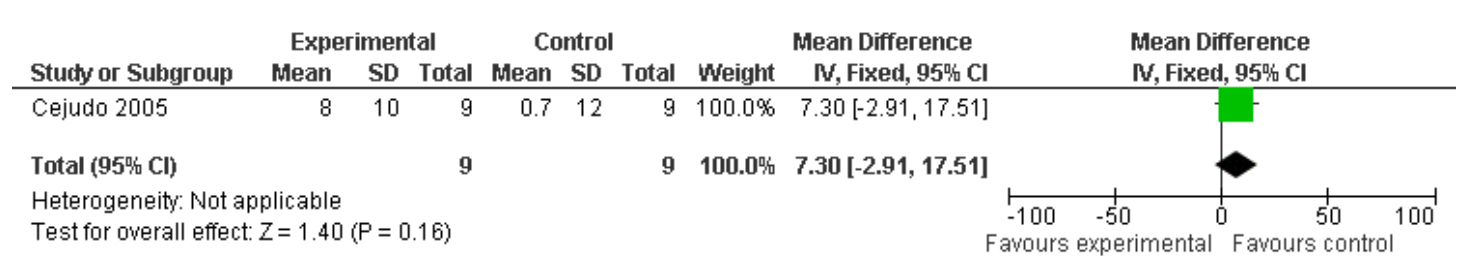

Primary outcome measure for aerobic exercise training: aerobic capacity, expressed in measures of work capacity

In the mitochondrial myopathy trial (Cejudo 2005), work capacity was measured in a cycle test and in the shuttle walking test. Endurance time was measured in a submaximal cycling test at a constant workload of $70 \%$ of the maximum power output achieved during the baseline incremental cycle test. The mean difference in time and distance cycled till exhaustion and leg fatigue or breathlessness exhaustion differed significantly between groups after 12 weeks. The mean differences in time and distance cycled till exhaustion between groups were 23.70 minutes (95\% CI 2.63 to 44.77) (Figure 12) and $9.70 \mathrm{~km}$ (95\% CI 1.51 to 17.89) (Figure 13), respectively. The distance walked until exhaustion was measured in the shuttle walking test. The mean difference between groups was 78.00 metres (95\% CI -144.86 to 300.86) (Figure 14).

Figure 12. Forest plot of comparison: 5 Aerobic exercise and strength training in mitochondrial myopathy, outcome: 5.4 Work capacity - mean time till exhaustion in cycle test.

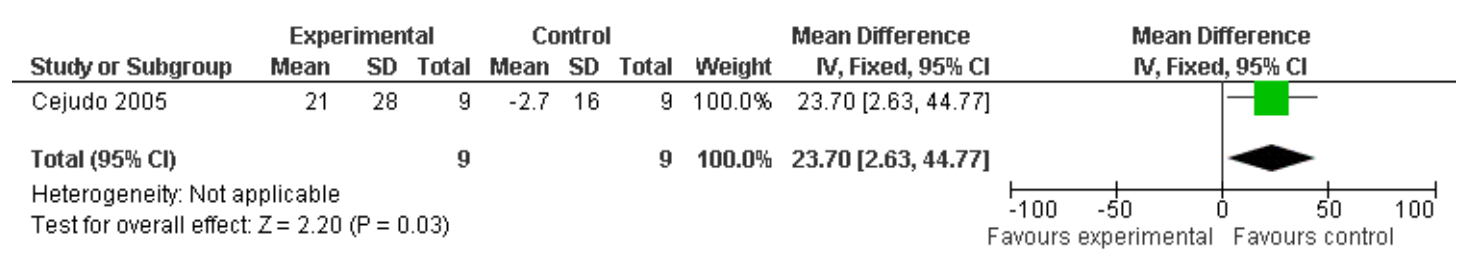


Figure 13. Forest plot of comparison: 5 Aerobic exercise and strength training in mitochondrial myopathy, outcome: 5.5 Work capacity- mean distance till exhaustion in cycle test.

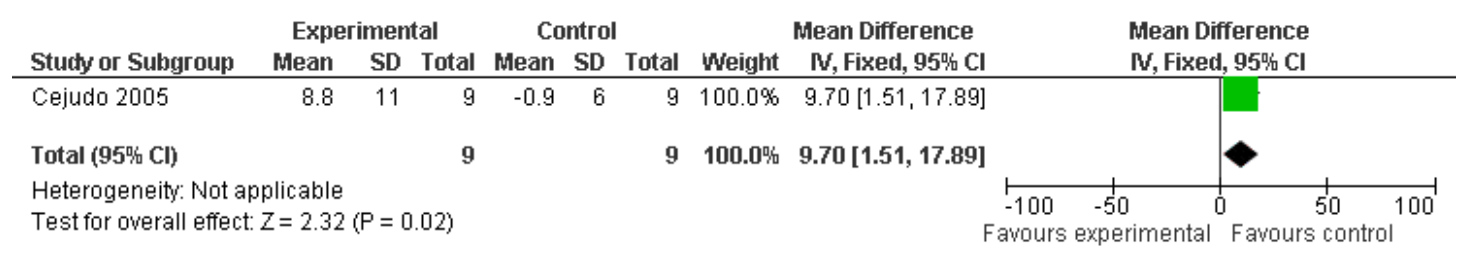

Figure 14. Forest plot of comparison: 5 Aerobic exercise and strength training in mitochondrial myopathy, outcome: 5.6 Work capacity - mean distance walked till exhaustion in shuttle walking test.

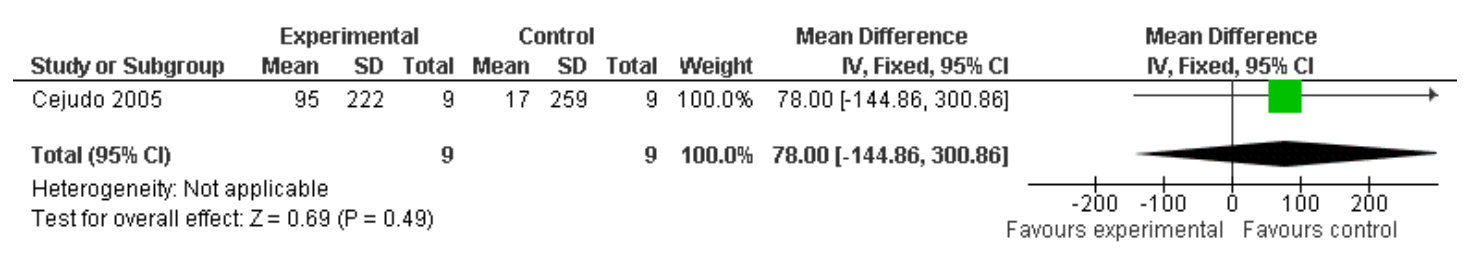
Secondary outcome measures for aerobic exercise or
strength training, or both:

\section{Aerobic capacity - expressed in measures of oxygen uptake (i.e. $\mathrm{VO}_{2}$ max)}

In the mitochondrial myopathy trial, oxygen uptake $\left(\mathrm{VO}_{2} \max \right)$ was noninvasively determined in a maximal incremental cycle exercise test (Cejudo 2005). $\mathrm{VO}_{2}$ max differed significantly between groups; mean difference was $14.60 \mathrm{ml} / \mathrm{min} / \mathrm{kg}$ ( $95 \%$ CI 8.70 to 20.80).

\section{Muscle strength - expressed in measures of endurance or fatigue}

This outcome was published for the myotonic dystrophy and facioscapulohumeral muscular dystrophy studies. In the myotonic dystrophy trial endurance was measured as maximum duration of contraction at $80 \%$ of mean voluntary isometric contraction. The difference between groups, 13.1 seconds (95\% CI 2.2 to 24.0 ) longer for the training group, was significant. This difference was mainly due to a decrease in endurance in the non-training group. In the facioscapulohumeral muscular dystrophy trial muscle endurance was expressed as a Force-Time Integral (FTI30) of a sustained 30 seconds maximal isometric contraction. The FTI30 of the elbow flexors did not differ significantly between the training and non-training group (mean difference right side $2 \mathrm{kgF.s}$, $95 \%$ CI -18 to 22 , in favour of the training group). The FTI30 of the ankle dorsiflexors decreased significantly and markedly in all treatment groups. This decrease was not influenced by training (mean difference right side $-1 \mathrm{kgF} . s, 95 \% \mathrm{CI}-42$ to 41 ). Changes in FTI30 for the left-sided trained muscle groups did not differ significantly from the right-sided results.

\section{(Time-scored) functional assessments of muscle} performance

This outcome was available for the myotonic dystrophy and facioscapulohumeral muscular dystrophy trials. In the myotonic dystrophy trial functional assessments comprised the following time-scored activities: ascending and descending stairs, rising from a chair, rising from supine, walking 50 metres as fast as possible, and walking 6 metres at natural speed. In the facioscapulohumeral muscular dystrophy trial the functional tests consisted of the assessment of a functional upper extremity grade and functional lower extremity grade (Personius 1994), and the following timedscored tasks: standing from lying supine, standing from sitting, walking 30 feet (9.14 metres), and climbing three standard stairs (Personius 1994). None of the outcomes demonstrated relevant or significant changes in mean differences between treatment groups in either trial. 


\section{Quality of life}

This outcome was assessed in the facioscapulohumeral muscular dystrophy trial using the Sickness Impact Profile (SIP) and the Symptom-Checklist (SCL-90-R). The mean total of the SIP and its subscales did not demonstrate relevant or significant changes for either the training or non-training groups. In addition, for both groups the mean SCL total did not change between the baseline and final visit. In the mitochondrial myopathy trial, the Nottingham Health Profile (NHP) questionnaire was used. Scores ranged from 0 (no problem) to 100 (maximum problem). The mean difference in overall score between both groups was -9.80 (95\% CI -25.70 to 6.14$)$.

\section{Parameters of muscle membrane permeability (serum creatine kinase level, serum myoglobin level)}

This outcome was available for the myotonic dystrophy and mitochondrial myopathy trial. In the myotonic dystrophy trial, serum myoglobin levels were assessed just before and one hour after the measurement session at the baseline visit and at the final visit. Changes in serum myoglobin activity one hour after a standardised test should reflect changes in muscle fibre permeability due to muscle damage. The mean rise in serum myoglobin levels did not differ significantly between the training and the non-training group (mean difference $-21.00 \mathrm{ng} / \mathrm{l}, 95 \% \mathrm{CI}-48.35$ to 6.35 ). In the mitochondrial myopathy trial, the authors state that serum creatine kinase levels of participants remained unaltered after the intervention period. However, data for the serum creatine kinase level were not published. In the facioscapulohumeral muscular dystrophy trial, one patient stopped training because of recurring, training-related muscle soreness and fatigue. A diagnostic work-up revealed a mitochondrial myopathy as well as facioscapulohumeral muscular dystrophy. In the mitochondrial myopathy trial, cancellations by participants happened because of muscle soreness associated with the exercise activity. However, every patient was able to tolerate the exercise training regimen without complications. In the myotonic dystrophy trial, a few participants complained of muscle soreness and transient strength reduction after eight weeks. However, no signs of muscle damage were found over the entire period of 24 weeks.

\section{Experienced pain}

This outcome was available in both the facioscapulohumeral muscular dystrophy and mitochondrial myopathy trials. In the facioscapulohumeral muscular dystrophy trial, 11 out of 34 participants in the training group reported pain in the neck and shoulder region to the physical therapist during home visits. Five people mentioned a period with elbow complaints. However, the number of people with neck-shoulder and elbow complaints did not differ between treatment groups at baseline nor at the final visit. Moreover, the number of participants with neck-shoulder and elbow complaints slightly decreased in both groups. Relative risk at the final visit was 1.02 (95\% CI 0.66 to 1.58$)$ for neck-shoulder and 1.82 (95\% CI 0.17 to 19.13$)$ for elbow complaints in favour of the non-training group. Although not formally quantified, the authors mentioned that participants experienced no notable muscle soreness after training. At the final visit, scores on the visual analogue scale for pain and the mean daily rated pain scores did not demonstrate significant changes for either group.

In the mitochondrial myopathy trial, participants' arm and leg myalgia were recorded in a simple questionnaire and scored as mild, moderate or severe. Two people in the exercise group and three people in the control group reported severe myalgia in arms and legs. Seven people in the exercise group and five people in the control group reported moderate myalgia in arms and legs. After the 12-week training programme no participants in the exercise group and five participants in the control group still reported symptoms of myalgia.

\section{Experienced fatigue}

In the facioscapulohumeral muscular dystrophy trial, experienced fatigue was measured by the fatigue severity subscale Checklist Individual Strength (CIS-fatigue). At the final visit, the mean score on the CIS-fatigue did not change significantly between the baseline and final visit for either group. The mean daily rated fatigue score of the participants in the training group slightly decreased, whereas the score in the non-training group showed a small increase.

In the mitochondrial myopathy trial, participants' usual fatigability was recorded in a simple questionnaire and scored as mild, moderate or severe. Three participants in the exercise group and five participants in the control group reported severe fatigue in arms and legs. At the end of the study period, no participants in the exercise group and five participants in the control group reported severe fatigue in arms and legs. Six participants in the exercise group and two participants in the control group reported moderate fatigue. After the intervention period, five participants in the exercise group and two participants in the control group still reported moderate fatigue.

\section{DISCUSSION}

Only five out of the 53 identified studies on the effect of training in people with muscle disease used a randomised controlled design. Two of these five trials were excluded because of a training duration of less than 10 weeks. The first excluded randomised controlled trial evaluated the effect of six weeks of cycle exercises and step aerobics in 14 people with polymyositis or dermatomyositis. After six weeks the peak isometric torque of the hip flexors and knee extensors, and the peak oxygen consumption differed significantly between the training and non-training group (mean difference of peak isometric torque $18.30 \mathrm{Nm}, 95 \% \mathrm{CI} 8.20$ to 
28.30, and mean difference of $\mathrm{VO}_{2} \max 14.60 \mathrm{ml} / \mathrm{min} / \mathrm{kg}, 95 \%$ CI 8.72 to 20.48, respectively) (Wiesinger 1998a). The second excluded randomised controlled trial evaluated the effect of homebased walking and strength training for eight weeks in 18 people with different muscle diseases. After eight weeks of training, only the mean difference in muscle strength of the right quadriceps reached statistical difference. The mean difference between groups was $4.26 \mathrm{~kg}$ (95\% CI 0.66 to 7.86). The mean difference of distance walked in the two minute walking test between groups was -11.62 metres (95\% CI -31.11 to 7.87), in favour of the control group (Dawes 2006). There is no evidence in the literature for excluding trials with a training duration of less than 10 weeks in muscle disease. Because the two studies with a training duration less than 10 weeks showed benefits, we will revise the protocol to include trials with a training duration of at least six weeks in a future update. Only three trials fulfilled the predefined criterion of a minimum of 10 weeks duration of training. The strength training trials in myotonic dystrophy and facioscapulohumeral muscular dystrophy participants had minor methodological shortcomings. The methodological quality for both strength training trials was therefore judged as adequate. In the facioscapulohumeral muscular dystrophy trial one of the main secondary outcome measures, the $1 \mathrm{RM}$ strength measurement, was performed by a physical therapist not blinded to the allocation to training or non-training. In the myotonic dystrophy trials diagnoses were not adequately verified. Furthermore, analysis in the myotonic dystrophy trial was not by intention-to-treat partly due to the matched-pair design. The methodological quality of the combined strength training and aerobic exercise trial in mitochondrial myopathy participants had several minor methodological shortcomings and was therefore judged as uncertain. In the mitochondrial myopathy trial, clinical evaluators were not blinded, which may have led to an overestimation of the training effect on muscle strength and aerobic capacity. Analysis in this trial was not by intention-to-treat.

Most mean differences in muscle strength outcomes (isometric, dynamic and endurance) between groups in all trials showed small, non-significant beneficial effects in favour of the training groups. Only changes in the endurance measure in the myotonic dystrophy trial ( 13.10 seconds longer maximum duration of an isometric contraction; $95 \%$ CI 2.20 to 24.00 ) and in the dynamic strength measure for the elbow flexors in the facioscapulohumeral muscular dystrophy trial (concentric contraction with $1.20 \mathrm{~kg}$ heavier weight; $95 \%$ CI 0.18 to 2.16 ) reached statistical significance. The absent or limited positive effects of strength training on muscle strength could reflect the inability of the diseased muscular system to respond with normal neural and hypertrophic adaptations to the applied training stimuli. However, part of this lack of response could be due to the specificity of the training (Lindeman 1995). All adaptations to training are specific to the stimuli applied. Specific strength training essentially involves exercising the muscles in the same manner as the expected use (Kraemer 2002). This means that a training programme with dynamic exercises increases dynamic strength more than isometric strength, and vice versa. This phenomenon of specificity of training has implications for the sensitivity of the outcome measures; e.g. the positive effect of a dynamic strength training programme may be captured by using a dynamic evaluation technique, but might be missed using an isometric strength measure. The size of the carry-over effect from, for example, dynamic strength to isometric strength cannot be predicted and it may be that there is a diminished ability of the diseased muscular system to transfer effects of a specific training programme from one strength modality to another (van der Kooi 2004). In the facioscapulohumeral muscular dystrophy trial, training did not influence strength of the ankle dorsiflexors, in contrast to the elbow flexors. The authors thought that a difference in grade of muscle weakness at baseline between elbow and ankle dorsiflexors might provide the explanation for the difference in their response to training. In this study elbow flexors were eligible for testing and training when strength according to the MRC scale grade was three or more, whereas ankle dorsiflexors were eligible when the muscles moved the ankle joint in a position between dorsiflexion and plantarflexion, which potentially includes MRC grades less than three (Medical Research Council 1981). Therefore, pre-exercise weakness might have been more severe in ankle dorsiflexors compared to elbow flexors. In patients with a muscle disease it is assumed that absolute gain in muscle strength resulting from strength training is probably related to pre-exercise muscle strength, and that severely weak muscles $(<10 \%$ of normal strength) may not be able to improve. However, this widely reported assumption is based on one published observation only (Milner-Brown 1988a). In the mitochondrial myopathy trial, the mean difference in aerobic capacity as measured in a submaximal cycle test differed significantly between the training and nontraining group after the study period. Participants in the training group cycled on average 23.70 minutes and 9.70 kilometres longer (95\% CI 2.63 to 44.77 and 1.51 to 17.89 , respectively) than participants in the control group. The distance walked in the shuttle walking test did not differ between groups. This could be explained by the specificity of training, because training consisted of cycling rather than walking exercises.

The timed-scored functional assessments did not demonstrate any relevant or significant changes in mean differences between treatment groups in either the myotonic dystrophy, or in the facioscapulohumeral muscular dystrophy trial. This may be due to the small number of muscle groups trained, the absent or limited effects on muscle strength, and the specificity of the training stimuli applied.

In all trials no signs of overuse, such as a decline in strength measures (Lindeman 1995; van der Kooi 2004), a rise in parameters of muscle membrane permeability (Lindeman 1995), or trainingrelated increase in pain or fatigue (van der Kooi 2004) were seen. This is of major clinical importance because these findings do not support the hypothesis of increased risk of muscle strain in 
these two slowly progressive muscular dystrophies. However, adverse events were only mentioned in general and not compared between groups. Moreover, several patients in all trials experienced muscle soreness. An enhanced liability for overwork weakness in more severely affected facioscapulohumeral muscular dystrophy patients cannot be excluded, because patients unable to walk independently were not included in the facioscapulohumeral muscular dystrophy trial. Furthermore, all strength training studies, including these three, imposed a controlled strain for a relatively short period. Hence, exertion of longer duration may still have an undetermined effect on disease progression.

Based on the evidence of the three selected randomised trials in this review concerning myotonic dystrophy (Lindeman 1995), facioscapulohumeral muscular dystrophy (van der Kooi 2004) and mitochondrial myopathy (Cejudo 2005), patients with these specific disorders can be advised that 'normal' participation in sports and work appears not to harm their muscles, but there is still insufficient evidence that it offers benefit. There is insufficient evidence for general prescription of strength training and aerobic exercise programmes in myotonic dystrophy and facioscapulohumeral muscular dystrophy, and some evidence in mitochondrial myopathy. Unfortunately, no clearly defined exercise protocols can be drawn from the current research evidence.

The results of the non-selected studies concerning other muscle diseases suggest a positive effect of strength training and do not point towards enhanced susceptibility concerning muscle overstrain, but limitations in the design of these studies prevent valid conclusions. The number of recent studies lacking a randomised controlled design is striking. At least for the relatively frequent muscle diseases one should aim for randomised controlled training studies. A non-exercised limb should not serve as a control, because of possible cross-education effects and a possible baseline difference in muscle weakness. More importantly, one can hardly expect meaningful effects of a single-limb training programme on daily activities, social participation and well-being of patients. While participants with different neuromuscular disorders can participate in the same study, the data should be presented and analysed individually for each specific muscle disease, as differences in the type of muscle disease may cause different responses to training. Specific diagnostic criteria should be given for all muscle diseases included. The severity of the impairments (loss of functions) should be presented to allow readers to assess the generalisability of the results to other patients. Although it may be difficult to quantify disease severity in some patients, ideally measures of disease severity should be presented as well, because differences among patients may strongly influence the outcome of training. In trials with a small sample size, participants should be stratified for disease severity. Another related characteristic that may influence outcome is the level of activity (sedentary versus active) at baseline, because in the healthy population untrained persons respond with higher percentages and rates of gain in strength, compared to trained individuals (Kraemer 2002).

The active training arm in trials could have additional non-specific benefits for the participants due to the regular interaction with a skilled therapist in contrast to the non-treatment group. This interaction may influence several outcome parameters, for example quality of life. Therefore, future studies should preferably have an appropriate control intervention rather than "no training" in order to assess the specific benefits of aerobic exercise and strength training exercise.

In strength training and aerobic exercise intervention studies, the training programme should be described in detail, just like the well-known prescription of drugs. Authors should provide information about the type(s) of exercises, the intensity (including progression rate), frequency, duration per exercise session, the duration of the entire programme, as well as trained muscle groups, and (about) the supervision of training. The recommendations from the ACSM Position Stand on 'The Recommended Quantity and Quality of Exercise for Developing and Maintaining Cardiorespiratory and Muscular Fitness, and Flexibility in Healthy Adults' (Pollock 1998) can be used as requirements to achieve an effective, safe and individualised exercise prescription taking into account the pre-training level of fitness. The ACSM recommendations were almost all adhered to by most of the included and excluded studies in this review. The only criterion that was rarely met was that eight to ten major muscle groups should be exercised in strength training programmes. This is probably partly due to limitations in time available to evaluate the effects of training by multiple assessments covering the different outcome measures. In addition, expenses for (adjusted) training equipment can be high. Thirdly, investigators were perhaps too cautious in order not to strain participants too much.

More studies on the effects of aerobic exercise and strength training programmes in specific muscle diseases on the basic level of muscle function and aerobic capacity are needed. There are wellvalidated outcome measures that are able to assess positive and at least equally important - negative effects on the diseased muscular system. The expertise to deliver training programmes is already present in sports medicine and experts in exercise physiology should be consulted. If strength training and aerobic exercise training programmes prove effective, we can then aim to develop and evaluate programmes adjusted to each different muscle disease. In patients with muscular disorders, combinations of muscle weakness, fatigue, pain and difficulty exercising can all lead to reduced physical activity and a sedentary lifestyle (McDonald 2002). Physical inactivity negatively impacts quality of life and health outcomes (McDonald 2002). In healthy young adults, the elderly, and in cardiac patients, increasing physical activity and participation in comprehensive exercise programmes incorporating aerobic activities, strength training and flexibility exercises has been shown to reduce the risk of several chronic diseases (e.g. coronary heart disease, obesity, diabetes and osteoporosis) (Kraemer 
2002). Therefore, indicators of chronic disease risk such as blood pressure, resting heart rate, body mass, glucose tolerance and bone density could be useful as additional outcome measures (Kilmer 2002), although little is known about the risks of comorbidity in patients with a muscle disease. Cost-benefit analyses are only relevant if the benefit of training is much higher than studies have shown so far.

In summary, the authors' recommendations for future studies are as follows.

- Participants with different muscle disorders can participate in one study, but data should be presented and analysed for each disease individually, and the power should be sufficient for each individual disorder.

- Randomised controlled comparisons should be made with participants having the same muscle disease. The effect of training in patients with a muscle disease should be compared to a non-exercising control group of patients with the same muscle disease and not to healthy individuals, or to contralateral nonexercised limbs.

- Stratification is strongly advised with regard to disease severity, particularly in studies with a small sample size. It should also be considered for pre-training level of activity (sedentary versus active, particularly in aerobic intervention studies).

- The following aspects of the training intervention should be specified: type(s) of exercise training, intensity and progression rate, frequency, duration per exercise session and of the entire programme, trained muscle groups, and supervision of training. Duration of the training intervention should be at least six weeks.

- Outcomes should at least include measures of muscle function (e.g. strength, endurance) and aerobic capacity (e.g. work capacity), and functional assessments. Researchers should be aware of the specificity of training effects in their choice of outcome measures. The following evaluations are strongly advised: measures of quality of life, experienced pain and experienced fatigue.
- Outcomes assessors should be blinded to avoid measurement bias.

- An appropriate placebo intervention is recommended in order to measure exercise-specific benefits.

\section{A U T HOR S, CONCLUSIONS Implications for practice}

Based on the evidence of three randomised trials in this review, moderate-intensity strength training in myotonic dystrophy (Lindeman 1995) and facioscapulohumeral muscular dystrophy (van der Kooi 2004) shows no significant benefit or harm. A combination of aerobic exercise and strength training in mitochondrial myopathy shows no harm and could be beneficial for aerobic capacity (Cejudo 2005). The small number of included studies and limitations in the design of studies in other muscle diseases prevent general conclusions in these disorders.

\section{Implications for research}

There is a need for more research to establish whether strength training and aerobic exercise training is beneficial in all forms of muscle disease, and to define the optimal exercise programmes for patients with a muscle disease.

\section{ACKNOWLEDGEMENTS}

The Netherlands Organisation for Scientific Research (NWO), the Health Research and Development Council of the Netherlands $(\mathrm{ZON})$ and the Prinses Beatrix Fonds (the Dutch Public Fund for Neuromuscular Disorders) for supporting three of the authors (Voet, van der Kooi, Lindeman) in related neuromuscular research projects.

Editorial support from the Cochrane Neuromuscular Disease Group was funded by the TREAT NMD European Union Grant 036825 .

\section{REFERENCES}

\section{References to studies included in this review}

Cejudo 2005 \{published data only\}

Cejduo P, Bautista J, Montemayor T, Villagomez R, Jimenez

L, Ortega F, et al.Exercise training in mitochondrial myopathy: a randomized clinical trial. Muscle \& Nerve 2005;32(3):342-50.

Lindeman 1995 \{published and unpublished data\} Lindeman E, Drukker J. Specificity of strength training in neuromuscular disorders. Journal of Rehabilitation Sciences
1994;7(3):13-5.

* Lindeman E, Leffers P, Spaans F, Drukker J, Reulen J, Kerckhoffs $M$, et al.Strength training in patients with myotonic dystrophy and hereditary motor and sensory neuropathy: a randomized clinical trial. Archives of Physical Medicine and Rehabilitation 1995;76(7):612-20. [MEDLINE: 95328927]

Lindeman E, Spaans F, Reulen J, Leffers P, Drukker

J. Progressive resistance training in neuromuscular patients. Effects on force and surface EMG. Journal of 
Electromyography and Kinesiology 1999;9(6):379-84.

van der Kooi 2004 \{published and unpublished data\} van der Kooi EL, Kalkman JS, Lindeman E, Hendriks JC, van Engelen BG, Bleijenberg G, et al.Effects of training and albuterol on pain and fatigue in facioscapulohumeral muscular dystrophy. Journal of Neurology 2007;254(7): $931-40$.

van der Kooi EL, Vogels OJM, van Asseldonk RJGP, Lindeman E, Hendriks JCM, Padberg GW. Strength training and albuterol in facioscapulohumeral muscular dystrophy. Neurology 2001;56(8 Suppl 3):A80 (abstract). van der Kooi EL, Vogels OJM, van Asseldonk RJGP, Lindeman E, Hendriks JCM, Padberg GW. The efficacy of strength training in facioscapulohumeral muscular dystrophy. Neurology 2000;54(Suppl 3):A435 (abstract). * van der Kooi EL, Vogels OJM, van Asseldonk RJGP, Lindeman E, Hendriks JCM, Wohlgemuth M, et al.Strength training and albuterol in facioscapulohumeral muscular dystrophy. Neurology 2004;63(4):702-8.

\section{References to studies excluded from this review}

\section{Abramson 1952 \{published data only\}}

Abramson AS, Rogoff J. An approach to the rehabilitation of children with muscular dystrophy. Physical treatment in muscular dystrophy. Proceedings 1st and 2nd Medical Conferences, Muscular Dystrophy Association of America. New York, 1952:123-5.

Aitkens 1993 \{published data only\} Aitkens SG, McCrory MA, Kilmer DD, Bernauer EM. Moderate resistance exercise program: its effect in slowly progressive neuromuscular disease. Archives of Physical Medicine and Rehabilitation 1993;74(7):711-5. [MEDLINE: 93319417]

Alexanderson 1999 \{published data only\} Alexanderson H, Stenström CH, Lundberg I. Safety of a home exercise programme in patients with polymyositis and dermatomyositis: a pilot study. Rheumatology 1999;38(7): 608-11. [MEDLINE: 99390573]

\section{Alexanderson 2000 \{published data only\}}

Alexanderson H, Stenström CH, Jenner G, Lundberg I. The safety of a resistive home exercise program in patients with recent onset active polymyositis or dermatomyositis. Scandinavian Journal of Rheumatology 2000;29(5):295-301. [MEDLINE: 20543924]

\section{Alexanderson 2007 \{published data only\}}

Alexanderson H, Dastmalchi M, Esbjornsson-Liljedahl $\mathrm{M}$, Opava $\mathrm{CH}$, Lundberg IE. Benefits of intensive resistance training in patients with chronic polymyositis or dermatomyositis. Arthritis and Rheumatism 2007;57(5): 768-77.

\section{Arnardottir 2003 \{published data only\}} Arnardottir S, Alexanderson H, Lundberg IE, Borg K. Sporadic inclusion body myositis: pilot study on the effects of a home exercise program on muscle function, histopathology and inflammatory reaction. Journal of
Rehabilitation Medicine 2003;35(1):31-5. [MEDLINE: 22498355]

\section{Dastmalchi 2007 \{published data only\}}

Dastmalchi M, Alexanderson H, Loell I, Stahlberg M, Borg K, Lundberg IE, et al.Effect of physical training on the proportion of slow-twitch type I muscle fibers, a novel nonimmune-mediated mechanism for muscle impairment in polymyositis or dermatomyositis. Arthritis Care and Research 2007;57(7):1303-10.

\section{Dawes 2006 \{published data only\}}

Dawes H, Korpershoek N, Freebody J, Elsworth C, van Tintelen N, Wade DT, et al.A pilot randomised controlled trial of a home-based exercise programme aimed at improving endurance and function in adults with neuromuscular disorders. Journal of Neurology, Neurosurgery and Psychiatry 2006;77(8):959-62.

\section{De Lateur 1979 \{published data only\}}

De Lateur BJ, Giaconi RM. Effect on maximal strength of submaximal exercise in Duchenne muscular dystrophy. American Journal of Physical Medicine 1979;58(1):26-36. [MEDLINE: 79163026]

\section{Escalante 1993 \{published data only\}} Escalante A, Miller L, Beardmore TD. An N-of-1 trial of resistive vs. non-resistive exercise in inflammatory muscle disease (IMD). Arthritis and Rheumatism 1991;34:S173.

* Escalante A, Miller L, Beardmore TD. Resistive exercise in the rehabilitation of polymyositis/dermatomyositis. Journal of Rheumatology 1993;20(8):1340-4. [MEDLINE: 94046853]

Florence 1984a \{published data only\} Florence JM, Hagberg JM. Effect of training on the exercise responses of neuromuscular disease patients. Medicine and Science in Sports and Exercise 1984;16(5):460-5. [MEDLINE: 85085458]

Florence 1984b \{published data only\} Florence JM, Brooke MH, Hagberg JM, Carroll JE. Endurance exercise in neuromuscular disease. In: Serratrice G editor(s). Neuromuscular Diseases. New York: Raven Press, 1984:577-81.

Fowler 1965 \{published data only\} Fowler WM, Pearson CM, Egstrom GH, Gardner GW. Ineffective treatment of muscular dystrophy with an anabolic steroid and other measures. New England Journal of Medicine 1965;272(17):875-82.

Heikkila 2001 \{published data only\} Heikkila S, Viitanen JV, Kautiainen H, Rajamaki T, Mantyvuo P, Harju T. Rehabilitation in myositis: preliminary study. Physiotherapy 2001;87:301-9.

Hicks 1989 \{published data only\} Hicks J, Miller F, Plotz P, Zdrojewski M, Chen T, Gerber L. Exercise in patients with polymyositis. Arthritis and Rheumatism 1989;32:S149. [MEDLINE: -]

Hoberman 1955 \{published data only\} Hoberman M. Physical medicine and rehabilitation: its value and limitations in progressive muscular dystrophy. American Journal of Physical Medicine 1955;34:109-15. 
Jeppesen 2006 \{published data only\}

Jeppesen TD, Schwartz M, Olsen DB, Wibrand F, Krag T, Duno $\mathrm{M}$, et al.Aerobic training is safe and improves exercise capacity in patients with mitochondrial myopathy. Brain 2006;129(12):3402-12.

Johnson 2007 \{published data only\} Johnson LG, Hons BS, Edwards DJ, Walters S, Thickbroom GW, Mastaglia FL. The effectiveness of an individualized, home-based functional exercise program for patients with sporadic inclusion body myositis. Journal of Clinical Neuromuscular Disease 2007;8(4):187-94.

Kelm 2001 \{published data only\}

Kelm J, Ahlhelm F, Regitz T, Pape D, Schmitt E. Controlled dynamic weight training in patients with neuromuscular disorders [Kontrolliertes dynamisches Krafttraining bei Patienten mit neuromuskulären Erkrankungen]. Fortschritte der Neurologie-Psychiatrie 2001;69(8):359-66. [MEDLINE: 21469372]

Kilmer 1994 \{published data only\} Kilmer DD, McCrory MA, Wright NC, Aitkens SG, Bernauer EM. The effect of a high resistance exercise program in slowly progressive neuromuscular disease. Archives of Physical Medicine and Rehabilitation 1994;75(5): 560-3. [MEDLINE: 94241849]

Kilmer 2005 \{published data only\} Kilmer DD, Wright NC, Aitkens S. Impact of a homebased activity and dietary intervention in people with slowly progressive neuromuscular diseases. Archives of Physical Medicine and Rehabilitation 2005;86(11):2150-6.

Lenman 1959 \{published data only\} Lenman JAR. A clinical and experimental study of the effects of exercise on motor weakness in neurological disease. Journal of Neurology, Neurosurgery, and Psychiatry 1959;22: 182-94. [MEDLINE: 60168364]

Mate-Munoz 2007 \{published data only\}

Mate-Munoz JL, Moran M, Perez M, Chamorro-Vina C, Gomez-Gallego F, Santiago C, et al.Favorable responses to acute and chronic exercise in McArdle patients. Clinical Journal of Sport Medicine 2007;17(4):297-303.

McCartney 1988 \{published data only\}

McCartney N, Moroz D, Garner SH, McComas AJ. The effects of strength training in patients with selected neuromuscular disorders. Medicine and Science in Sports and Exercise 1988;20(4):362-8. [MEDLINE: 89013826]

Mielke 1990 \{published data only\}

Mielke U, Leipnitz, Holzer H, Schimrigk K. Dynamic muscular training in neuromuscular disease. Journal of the Neurological Sciences 1990;S98:388.

Milner-Brown 1988a \{published data only\} Milner-Brown HS, Miller RG. Muscle strengthening through high-resistance weight training in patients with neuromuscular disorders. Archives of Physical Medicine and Rehabilitation 1988;69(1):14-9. [MEDLINE: 88105930]

Milner-Brown 1988b \{published data only\} Milner-Brown HS, Miller RG. Muscle strengthening through electric stimulation combined with low-resistance weights in patients with neuromuscular disorders. Archives of Physical Medicine Rehabilitation 1988;69(1):20-4. [MEDLINE: 88105931]

Milner-Brown 1990 \{published data only\} Milner-Brown HS, Miller RG. Myotonic dystrophy: quantification of muscle weakness and myotonia and the effect of amitriptyline and exercise. Archives of Physical Medicine and Rehabilitation 1990;71(12):983-7. [MEDLINE: 91053719]

Murphy 2008 \{published data only\} Murphy JL, Blakely EL, Schaefer AM, He L, Wyrick P, Haller RG, et al.Resistance training in patients with single, large-scale deletions of mitochondrial DNA. Brain 2008; 131(Pt 11):2832-40.

Na 1996 \{published data only\}

Na YM, Kang SW, Lee HS, Moon JH. The effect of home exercise program for patients with myotonic dystrophy. Journal of the Korean Academy of Rehabilitation Medicine 1996;20(1):33-8.

Olsen 2005 \{published data only\}

Olsen DB, Orngreen MC, Vissing J. Aerobic training improves exercise performance in facioscapulohumeral muscular dystrophy. Neurology 2005;64(6):1064-6.

Orngreen 2005 \{published data only\}

Orngreen MC, Olsen DB, Vissing J. Aerobic training in patients with myotonic dystrophy type 1. Annals of Neurology 2005;57(5):754-7.

Scott 1981 \{published data only\}

Dubowitz V, Hyde SA, Scott OM, Goddard C. In: Serratrice G, et al. eds editor(s). Neuromuscular Diseases. New York: Raven Press, 1984:571-575.

* Scott OM, Hyde SA, Goddard C, Jones R, Dubowitz V. Effect of exercise in Duchenne muscular dystrophy. Physiotherapy 1981;67(6):174-6. [MEDLINE: 82060752]

Siciliano 2000 \{published data only\} Siciliano G, Manca ML, Renna M, Prontera C, Mercuri A, Murri L. Effects of aerobic training on lactate and catecholaminergic exercise responses in mitochondrial myopathies. Neuromuscular Disorders 2000;10(1):40-5. [MEDLINE: 20142352]

\section{Spector 1997 \{published data only\}} Spector SA, Lemmer JT, Koffman BM, Fleischer TA, Feuerstein IM, Hurley BF, et al.Safety and efficacy of strength training in patients with sporadic inclusion body myositis. Muscle \& Nerve 1997;20(10):1242-8. [MEDLINE: 97464259]

Sunnerhagen 2004 \{published data only\} Sunnerhagen KS, Darin N, Tajsharghi H, Oldfors A. The effects of endurance training in persons with a hereditary myosin myopathy. Acta Neurologica Scandinavica 2004;110 (2):80-6.

Sveen 2007 \{published data only\} Sveen ML, Jeppesen TD, Hauerslev S, Krag TO, Vissing $\mathrm{J}$. Endurance training: an effective and safe treatment for patients with LGMD2I. Neurology 2007;68(1):59-61. 
Sveen 2008 \{published data only\}

Sveen ML, Jeppesen TD, Hauerslev S, Kober L, Krag TO, Vissing J. Endurance training improves fitness and strength in patients with Becker muscular dystrophy. Brain 2008; 131(Pt 11):2824-31.

\section{Taivassalo 1998 \{published data only\}}

Taivassalo T, De Stefano N, Argov Z, Matthews PM, Chen $\mathrm{J}$, Genge A, et al.Effects of aerobic training in patients with mitochondrial myopathies. Neurology 1998;50(4): 1055-60. [MEDLINE: 98226045]

\section{Taivassalo 1999 \{published data only\}} Taivassalo T, De Stefano N, Chen J, Karpati G, Arnold DL, Argov Z. Short-term aerobic training response in chronic myopathies. Muscle \& Nerve 1999;22(9):1239-43.

Taivassalo 2001 \{published data only\} Taivassalo T, Shoubridge EA, Chen J, Eng M, Kennaway NG, DiMauro $S$, et al.Aerobic conditioning in patients with mitochondrial myopathies: physiological, biochemical, and genetic effects. Annals of Neurology 2001;50(2):133-41.

Taivassalo 2006 \{published data only\}

Taivassalo T, Gardner JL, Taylor RW, Schaefer AM, Newman J, Barron MJ, et al.Endurance training and detraining in mitochondrial myopathies due to single largescale mtDNA deletions. Brain 2006;129(12):3391-401.

\section{Tollbäck 1999 \{published data only\}}

Tollbäck A, Eriksson S, Wredenberg A, Jenner G, Vargas $\mathrm{R}$, Borg K, et al.Effects of high resistance training in patients with myotonic dystrophy. Scandinavian Journal of Rehabilitation Medicine 1999;31(1):9-16. [MEDLINE: 99246613]

\section{Trenell 2006 \{published data only\}}

Trenell MI, Sue CM, Kemp GJ, Sachinwalla T, Thompson $\mathrm{CH}$. Aerobic exercise and muscle metabolism in patients with mitochondrial myopathy. Muscle and Nerve 2006;33 (4):524-31.

Varju 2003 \{published data only\}

Varju C, Petho E, Kutas R, Czirjak L. The effect of physical exercise following acute disease exacerbation in patients with dermatomyositis/polymyositis. Clinical Rehabilitation 2003;17(1):83-7.

Vignos 1966 \{published data only\}

Vignos PJ Jr, Watkins MP. The effect of exercise in muscular dystrophy. JAMA 1966;197(11):843-8. [MEDLINE: 66170941]

Wiesinger 1998a \{published data only\} Wiesinger GF, Quittan M, Aringer M, Seeber A, VolcPlatzer B, Smolen J, et al.Improvement of physical fitness and muscle strength in polymyositis/dermatomyositis patients by a training programme. British Journal of Rheumatology 1998;37(2):196-200. [MEDLINE: 98228031]

Wiesinger 1998b \{published data only\}

Wiesinger GF, Quittan M, Graninger M, Seeber A, Ebenbichler G, Sturm B, et al.Benefit of 6 months longterm physical training in polymyositis/dermatomyositis patients. British Journal of Rheumatology 1998;37(12): 1338-42. [MEDLINE: 99137446]

Wright 1996 \{published data only\}

Wright NC, Kilmer DD, McCrory MA, Aitkens SG, Holcomb BJ, Bernauer EM. Aerobic walking in slowly progressive neuromuscular disease: effect of a 12-week program. Archives of Physical Medicine and Rehabilitation 1996;77(1):64-9. [MEDLINE: 96143273]

Yildirim 2007 \{published data only\}

Yildirim S, Erden Z, Kilinc M. Comparison of the effects of proprioceptive neuromuscular facilitation techniques and weight training in patients with neuromuscular diseases. Fizyoterapi Rehabilitasyon 2007;18(2):65-71.

\section{Additional references}

\section{Brouwer 1992}

Brouwer OF, Padberg GW, van der Ploeg RJ, Ruys CJ, Brand R. The influence of handedness on the distribution of muscular weakness of the arm in facioscapulohumeral muscular dystrophy. Brain 1992;115(Pt 5):1587-98. [MEDLINE: 93045457]

\section{Deidda 1996}

Deidda G, Cacurri S, Piazzo N, Felicetti L. Direct detection of 4q35 rearrangements implicated in facioscapulohumeral muscular dystrophy (FSHD). Journal of Medical Genetics 1996;33(5):361-5.

\section{Emery 1997}

Emery AEH. Diagnostic Criteria for Neuromuscular Disorders. 2nd Edition. London: Royal Society of Medicine Press, 1997. [: ISBN $185315301 \mathrm{X}$ ]

\section{Fowler 1982}

Fowler WM Jr, Taylor M. Rehabilitation management of muscular dystrophy and related disorders: I. The role of exercise. Archives of Physical Medicine and Rehabilitation 1982;63(7):319-21. [MEDLINE: 82230478]

\section{Fowler 1984}

Fowler WM Jr. Importance of overwork weakness. Muscle \& Nerve 1984;7(6):496-9. [MEDLINE: 86014181]

\section{Higgins 2008}

Higgins JPT, Green S, editors. Cochrane Handbook for Systematic Reviews of Interventions. The Cochrane Collaboration 2008. Available from www.cochranehandbook.org, 2008. Version 5.0.1 [updated September 2008]..

\section{Johnson 1971}

Johnson EW, Braddom R. Over-work weakness in facioscapulohumeral muscular dystrophy. Archives of Physical Medicine and Rehabilitation 1971;52(7):333-6. [MEDLINE: 71277095]

\section{Kilmer 1998}

Kilmer DD. The role of exercise in neuromuscular disease. Physical Medicine and Rehabilitation Clinics of North America 1998;9(1):115-25. [MEDLINE: 99109702] 


\section{Kilmer 2002}

Kilmer DD. Response to aerobic exercise training in humans with neuromuscular disease. American Journal of Physical Medicine \& Rehabilitation 2002;81(Suppl 11):148-50.

\section{Kraemer 2002}

Kraemer WJ, Adams K, Carfarellil E, Dudley GA, Dooly C, Feigenbaum MS, Fleck SL, et al.American College of Sports Progression models in resistance training for healthy adults. Medicine and Science in Sports and Exercise 2002;34 (2):364-80.

\section{Lee 2007}

Lee M, Carroll TJ. Cross education: possible mechanisms for the contralateral effects of unilateral resistance training. Sports Medicine 2007;37(1):1-14.

\section{McDonald 2002}

McDonald CM. Physical activity, health impairments, and disability in neuromuscular disease. American Journal of Physical Medicine \& Rehabilitation 2002;81(Suppl 11): S108-20.

\section{Medical Research Council 1981}

Medical Research Council. Aids to investigation of peripheral nerve injuries. London: Her Majesty's Stationary Office, 1981.

\section{Munn 2004}

Munn J, Herbert RD, Gandevia SC. Contralateral effects of unilateral resistance training: a meta-analysis. Journal of Applied Physiology 2004;96(5):1861-6.

\section{Munn 2005}

Munn J, Herbert RD, Hancock MJ, Gandevia SC. Training with unilateral resistance exercise increases contralateral strength. Journal of Applied Physiology 2005;99(5):1880-4.

\section{Personius 1994}

Personius KE, Pandya S, King WM, Tawil R, McDermott MP. Facioscapulohumeral dystrophy natural history study: standardization of testing procedures and reliability of measurements. The FSH DY Group. Physical Therapy 1994;74(3):253-63.

\section{Pollock 1998}

Pollock M, Gaesser G, Butcher J, Dishman J-P, Franklin B, Garber C. Position stand on the recommended quantity and quality of exercise for developing and maintaining cardiorespiratory and muscular fitness, and flexibility in healthy adults. Medicine and Science in Sports and Exercise 1998;30(6):975-91. [MEDLINE: 98287757 98287757]

\section{RevMan 2008}

The Nordic Cochrane Centre. The Cochrane Collaboration. Review Manager (RevMan). 5.0. Copenhagen: The Nordic Cochrane Centre. The Cochrane Collaboration, 2008.

\section{Sale 1988}

Sale DG. Neural adaptation to resistance training. Medicine and Science in Sports and Exercise 1988;20(Suppl 5):135-45.

\section{Saunders 2004}

Saunders DH, Greig CA, Young A, Mead GE. Physical fitness training for stroke patients. Cochrane Database of Systematic Reviews 2004, Issue 1. [Art. No.: CD003316. DOI: 10.1002/14651858.CD003316.pub2]

\section{Shima 2002}

Shima N, Ishida K, Katayama K, Morotome Y, Sato Y, Miyamura M. Cross education of muscular strength during unilateral resistance training and detraining. European Journal of Applied Physiology 2002;86(4):287-94.

\section{USDHHS 1996}

U.S. Department of Health and Human Services, Centers for Disease Control and Prevention, National Center for Chronic Disease Prevention and Health Promotion. Physical activity and health: a report of the surgeon general. Atlanta: Centers for Disease Control and Prevention, 1996

\section{Vignos 1983}

Vignos PJ Jr. Physical models of rehabilitation in neuromuscular disease. Muscle \& Nerve 1983;6(5):323-38. [MEDLINE: 83297471]

* Indicates the major publication for the study 
CHARACTERISTICS OF STUDIES

Characteristics of included studies [ordered by study ID]

Cejudo 2005

\begin{tabular}{l|l}
\hline Methods & Parallel group randomised clinical trial \\
\hline Participants & 20 adults with mitochondrial myopathy \\
\hline Interventions & Strength training and aerobic exercise training versus no training \\
\hline Outcomes & $\begin{array}{l}\text { Primary: exercise capacity - expressed in measures of oxygen uptake (i.e. VO } \mathrm{VO}_{2} \text { max), } \\
\text { endurance time and distance walked in the shuttle walking test. Secondary outcomes } \\
\text { were: peripheral muscle strength (1RM test), quality of life, symptoms of myalgia, cramps } \\
\text { and fatigability and functional exercise capacity }\end{array}$ \\
\hline Notes & - \\
\hline
\end{tabular}

Risk of bias

\begin{tabular}{|c|c|c|}
\hline Bias & Authors' judgement & Support for judgement \\
\hline $\begin{array}{l}\text { Random sequence generation (selection } \\
\text { bias) }\end{array}$ & Low risk & $\begin{array}{l}\text { Quote: "Patients were randomly assigned to a } \\
\text { training group or control group" } \\
\text { Comment: no published information on the } \\
\text { sequence generation. The author (Cejudo) in- } \\
\text { formed us that patients were randomly as- } \\
\text { signed according to a computer generated ran- } \\
\text { domisation list }\end{array}$ \\
\hline Allocation concealment (selection bias) & Low risk & $\begin{array}{l}\text { Quote: "Patients were randomly assigned to a } \\
\text { training group or control group" } \\
\text { Comment: no published information on the } \\
\text { allocation concealment. The author (Cejudo) } \\
\text { informed us that patients were randomly as- } \\
\text { signed according to a computer generated ran- } \\
\text { domisation list }\end{array}$ \\
\hline
\end{tabular}

Blinding (performance bias and detection High risk bias)

All outcomes

Incomplete outcome data (attrition bias) High risk All outcomes
Comment: no published information on the blinding of the outcome assessors and personnel. The author (Cejudo) told us that the evaluators knew to which group each patient was assigned

Quote: “...one patient in each group failed to finish the study for personal reasons" Comment: baseline outcome data assessed, but not available for these patients. So $1 / 10$ missing from intervention group and $1 / 10$ 
Cejudo 2005 (Continued)

missing from control group

\begin{tabular}{ll|l}
\hline Selective reporting (reporting bias) & High risk & missing from control group \\
\hline Other bias & Low risk & $\begin{array}{l}\text { No primary and secondary outcome(s) de- } \\
\text { fined in the article }\end{array}$ \\
\hline
\end{tabular}

Lindeman 1995

\begin{tabular}{l|l}
\hline Methods & Evaluator blind, matched-control, randomised controlled trial \\
\hline Participants & 36 adults with myotonic dystrophy (2 congenital form, 34 classical type) \\
\hline Interventions & Strength training versus no training \\
\hline Outcomes & $\begin{array}{l}\text { Primary: muscle strength by isokinetically measured knee torques and isometrically as } \\
\text { maximum voluntary contraction (MVIC). Main secondary outcomes were: endurance } \\
\text { by maximum duration of contraction at } 80 \% \text { of MVIC, functional performance by } \\
\text { timed motor performance tests and by questionnaires. Serum myoglobin levels to detect } \\
\text { changes in muscle fibre membrane permeability }\end{array}$ \\
\hline
\end{tabular}

Notes

Participants were matched based on muscle strength (knee extension torque/body weight) and on performance in a stair-climbing test. Only complete pairs were analysed

\section{Risk of bias}

\begin{tabular}{|c|c|c|}
\hline Bias & Authors' judgement & Support for judgement \\
\hline $\begin{array}{l}\text { Random sequence generation (selection } \\
\text { bias) }\end{array}$ & Low risk & $\begin{array}{l}\text { Comment: there was no published infor- } \\
\text { mation on the sequence generation but the } \\
\text { author (Lindeman) informed us that } 2 \text { in- } \\
\text { dependent persons drew a sealed lot per } \\
\text { matched pair and allocated it by tossing a } \\
\text { coin to the training or non-training group }\end{array}$ \\
\hline Allocation concealment (selection bias) & Low risk & $\begin{array}{l}\text { Comment: there was no published infor- } \\
\text { mation on the method of allocation con- } \\
\text { cealment but the author (Lindeman) in- } \\
\text { formed us that } 2 \text { independent persons al- } \\
\text { located the training, after tossing the coin, } \\
\text { to the training or non-training group }\end{array}$ \\
\hline
\end{tabular}

Blinding (performance bias and detection Low risk bias)

All outcomes
Quote: "observers of the outcome measurements were blinded for treatment allocation"

Comment: approximately $20 \%$ of the myotonic dystrophy participants revealed information to the clinical evaluators that re- 
Lindeman 1995 (Continued)

\begin{tabular}{|c|c|c|}
\hline & & $\begin{array}{l}\text { sulted in unblinding during the course of } \\
\text { the trial }\end{array}$ \\
\hline $\begin{array}{l}\text { Incomplete outcome data (attrition bias) } \\
\text { All outcomes }\end{array}$ & High risk & $\begin{array}{l}3 \text { of the initially } 36 \text { randomised partici- } \\
\text { pants withdrew before disclosure of treat- } \\
\text { ment allocation. The } 33 \text { participants start- } \\
\text { ing the trial made } 15 \text { matched pairs. Dur- } \\
\text { ing the trial } 1 \text { person dropped out. Because } \\
\text { of the matched pair design only complete } \\
\text { pairs were analysed, therefore eventually } 28 \\
\text { of the initial } 36 \text { randomised participants } \\
\text { were analysed. Follow up was therefore in- } \\
\text { complete and analysis was not by 'inten- } \\
\text { tion-to-treat'. However, the flow path of } \\
\text { participants was well documented }\end{array}$ \\
\hline Selective reporting (reporting bias) & Low risk & No evidence found for selective reporting \\
\hline Other bias & Low risk & No risk of bias from other sources detected \\
\hline
\end{tabular}

van der Kooi 2004

Methods

Participants

Interventions

Outcomes

Primary: difference in muscle strength of elbow flexors and ankle dorsiflexors after
52 weeks using the maximum voluntary isometric strength (MVIC). Main secondary
outcomes were muscle endurance (MVIC Force-Time Integral) and dynamic muscle
strength (1RM). Other measures included functional tests and timed motor performance
tasks

Evaluator blind, parallel group, randomised controlled trial

65 adults with facioscapulohumeral muscular dystrophy

Strength training versus no training (and as add-on in a double blind randomised controlled design albuterol or placebo)

\begin{tabular}{ll} 
Notes & $\begin{array}{l}\text { Outcomes are presented for the } 4 \text { treatment groups (i.e. the } 4 \text { combinations of training } \\
\text { versus non-training, and albuterol versus placebo). Effect sizes are presented by inter- } \\
\text { vention as well }\end{array}$ \\
\hline
\end{tabular}

\section{Risk of bias}

\begin{tabular}{|c|c|c|}
\hline Bias & Authors' judgement & Support for judgement \\
\hline $\begin{array}{l}\text { Random sequence generation (selection } \\
\text { bias) }\end{array}$ & Low risk & $\begin{array}{l}\text { Quote: "...participants were randomly as- } \\
\text { signed to one of the four treatment groups } \\
\text { according to a computer generated ran- } \\
\text { domisation list" }\end{array}$ \\
\hline
\end{tabular}


van der Kooi 2004 (Continued)

\begin{tabular}{|c|c|c|}
\hline Allocation concealment (selection bias) & Low risk & $\begin{array}{l}\text { Quote: "information on the assignment to } \\
\text { training or non-training was disclosed to } \\
\text { the participants by the physical therapist" }\end{array}$ \\
\hline $\begin{array}{l}\text { Blinding (performance bias and detection } \\
\text { bias) } \\
\text { All outcomes }\end{array}$ & Low risk & $\begin{array}{l}\text { Quote: "The RM measurements were per- } \\
\text { formed by the physical therapist, who was } \\
\text { not blinded for the allocation to training or } \\
\text { non-training, as this specific measurement } \\
\text { carried too great a risk of unblinding the } \\
\text { clinical evaluator" } \\
\text { Comment: adequate although one of the } \\
\text { main secondary outcome measures, the one } \\
\text { repetition maximum (1RM) measurement } \\
\text { for assessing dynamic strength, was per- } \\
\text { formed by the physical therapist, who su- } \\
\text { pervised the training, and was therefore not } \\
\text { blinded to the allocation to training or non- } \\
\text { training. Unblinding during the trial was } \\
\text { adequately registered. Allocation to train- } \\
\text { ing or non-training was unmasked in } 3 \\
\text { cases, due to unintentional remarks }\end{array}$ \\
\hline
\end{tabular}

Incomplete outcome data (attrition bias) Low risk

All outcomes

Quote: “One patient stopped training because of recurring, training-related muscle soreness and fatigue. Four participants stopped using their study medication because of side effects. Data for the participants who discontinued an intervention were analysed in the assigned treatment group"

Comment: complete follow up of all participants

\begin{tabular}{|c|c|c|}
\hline Selective reporting (reporting bias) & Low risk & No evidence found for selective reporting \\
\hline Other bias & Low risk & No risk of bias from other sources detected \\
\hline
\end{tabular}

Characteristics of excluded studies [ordered by study ID]

\begin{tabular}{ll}
\hline Study & Reason for exclusion \\
\hline Abramson 1952 & Not a randomised controlled trial \\
\hline Aitkens 1993 & $\begin{array}{l}\text { Not a randomised controlled trial. Exercised versus non-exercised control limb (randomly assigned) and } \\
\text { patients versus healthy volunteers }\end{array}$
\end{tabular}


(Continued)

\begin{tabular}{|c|c|}
\hline Alexanderson 1999 & Pilot study. Not a randomised controlled trial. \\
\hline Alexanderson 2000 & Extension of a pilot study Alexanderson 1999. Not a randomised controlled trial. \\
\hline Alexanderson 2007 & Not a randomised controlled trial. Training programme duration of 7 weeks \\
\hline Arnardottir 2003 & Not a randomised controlled trial \\
\hline Dastmalchi 2007 & Not a randomised controlled trial \\
\hline Dawes 2006 & Training duration of 8 weeks \\
\hline De Lateur 1979 & Not a randomised controlled trial. Exercised versus non-exercised control limb (randomly assigned) \\
\hline Escalante 1993 & Not a randomised controlled trial \\
\hline Florence $1984 \mathrm{a}$ & Not a randomised controlled trial \\
\hline Florence $1984 \mathrm{~b}$ & Not a randomised controlled trial \\
\hline Fowler 1965 & Not a randomised controlled trial. Exercise combined with medication \\
\hline Heikkila 2001 & Not a randomised controlled trial. Training programme duration of 3 weeks \\
\hline Hicks 1989 & Not a randomised controlled trial. Training programme duration of 1 month \\
\hline Hoberman 1955 & $\begin{array}{l}\text { Not a randomised controlled trial. } 3 \text { drugs added to a comprehensive regimen of therapies, including breathing } \\
\text { and resistive exercises }\end{array}$ \\
\hline Jeppesen 2006 & Not a randomised controlled trial \\
\hline Johnson 2007 & Not a randomised controlled trial \\
\hline Kelm 2001 & Not a randomised controlled trial. Training programme duration of 6 weeks \\
\hline Kilmer 1994 & $\begin{array}{l}\text { Not a randomised controlled trial. Exercised versus non-exercised control limb (randomly assigned) and } \\
\text { patients versus healthy volunteers }\end{array}$ \\
\hline Kilmer 2005 & Not a randomised controlled trial \\
\hline Lenman 1959 & $\begin{array}{l}\text { Not a randomised controlled trial. Training programme duration for patients with muscle disorders ranged } \\
\text { from approximately } 1 \text { to } 21 \text { months }\end{array}$ \\
\hline Mate-Munoz 2007 & Not a randomised controlled trial \\
\hline McCartney 1988 & $\begin{array}{l}\text { Not a randomised controlled trial. Exercised versus non-exercised control limb (randomly assigned). Training } \\
\text { programme duration of } 9 \text { weeks }\end{array}$ \\
\hline
\end{tabular}


(Continued)

\begin{tabular}{|c|c|}
\hline Mielke 1990 & Not a randomised controlled trial. Training programme duration of 6 weeks \\
\hline Milner-Brown 1988a & $\begin{array}{l}\text { Not a randomised controlled trial. Training programme duration for patients with muscle disorders ranged } \\
\text { from approximately } 2 \text { to } 48 \text { months }\end{array}$ \\
\hline Milner-Brown 1988b & $\begin{array}{l}\text { Not a randomised controlled trial. Intervention is not training versus non-training, but training added to } \\
\text { electric stimulation or electric stimulation only in } 1 \text { limb versus a non-stimulated, non-exercised control limb }\end{array}$ \\
\hline Milner-Brown 1990 & $\begin{array}{l}\text { Not a randomised controlled trial. Intervention is not training versus no training, but amitriptyline added } \\
\text { to strength training }\end{array}$ \\
\hline Murphy 2008 & Not a randomised controlled trial \\
\hline Na 1996 & $\begin{array}{l}\text { Not a randomised controlled trial. Intervention is not training versus non-training, but training and daily } \\
\text { quinine sulfate }\end{array}$ \\
\hline Olsen 2005 & Not a randomised controlled trial \\
\hline Orngreen 2005 & Not a randomised controlled trial \\
\hline Scott 1981 & $\begin{array}{l}\text { A randomised controlled trial that makes a comparison between } 2 \text { different training regimes. No comparison } \\
\text { of training versus non-training patients }\end{array}$ \\
\hline Siciliano 2000 & Not a randomised controlled trial \\
\hline Spector 1997 & Not a randomised controlled trial \\
\hline Sunnerhagen 2004 & Not a randomised controlled trial. Training programme duration 8 weeks \\
\hline Sveen 2007 & Not a randomised controlled trial \\
\hline Sveen 2008 & Not a randomised controlled trial \\
\hline Taivassalo 1998 & Not a randomised controlled trial. Training programme duration of 8 weeks \\
\hline Taivassalo 1999 & Not a randomised controlled trial. Training programme duration of 8 weeks \\
\hline Taivassalo 2001 & Not a randomised controlled trial \\
\hline Taivassalo 2006 & Not a randomised controlled trial \\
\hline Tollbäck 1999 & Not a randomised controlled trial. Exercised versus non-exercised control limb (randomly assigned) \\
\hline Trenell 2006 & Not a randomised controlled trial \\
\hline Varju 2003 & Not a randomised controlled trial. Training programme duration of 3 weeks \\
\hline Vignos 1966 & Not a randomised controlled trial \\
\hline
\end{tabular}




\section{(Continued)}

\begin{tabular}{ll}
\hline Wiesinger 1998a & Training duration of 6 weeks \\
\hline Wiesinger 1998b & A non-randomised extension of a randomised controlled trial (Wiesinger 1998a). \\
\hline Wright 1996 & Not a randomised controlled trial \\
\hline Yildirim 2007 & Not a randomised controlled trial \\
\hline
\end{tabular}


DATA AND ANALYSES

Comparison 1. Strength training versus control in myotonic dystrophy

\begin{tabular}{lcccc} 
Outcome or subgroup title & $\begin{array}{c}\text { No. of } \\
\text { studies }\end{array}$ & $\begin{array}{c}\text { No. of } \\
\text { participants }\end{array}$ & Statistical method & Effect size \\
\hline $\begin{array}{c}1 \text { Muscle strength - maximum } \\
\text { isotonic knee torque extension }\end{array}$ & 1 & 28 & Mean Difference (IV, Fixed, 95\% CI) & $3.9[-4.11,11.91]$ \\
$\begin{array}{c}2 \text { Muscle strength - maximum } \\
\text { isotonic knee torque flexion }\end{array}$ & 1 & 28 & Mean Difference (IV, Fixed, 95\% CI) & $3.70[-3.78,11.18]$ \\
$\begin{array}{c}3 \text { Muscle strength - maximum } \\
\text { isometric voluntary contraction }\end{array}$ & 1 & 28 & Mean Difference (IV, Fixed, 95\% CI) & $2.10[-7.52,11.72]$ \\
\hline
\end{tabular}

Comparison 2. Strength training versus control in facioscapulohumeral muscular dystrophy

\begin{tabular}{lcccc} 
Outcome or subgroup title & $\begin{array}{c}\text { No. of } \\
\text { studies }\end{array}$ & $\begin{array}{c}\text { No. of } \\
\text { participants }\end{array}$ & Statistical method & Effect size \\
\hline $\begin{array}{c}\text { 1 Muscle strength elbow flexors - } \\
\text { maximum voluntary isometric } \\
\text { contraction }\end{array}$ & 1 & 65 & Mean Difference (IV, Fixed, 95\% CI) & $0.54[-0.38,1.46]$ \\
$\begin{array}{c}2 \text { Muscle strength elbow flexors - } \\
\text { dynamic strength }\end{array}$ & 1 & 65 & Mean Difference (IV, Fixed, 95\% CI) & $1.17[0.18,2.16]$ \\
$\begin{array}{c}3 \text { Muscle strength ankle } \\
\text { dorsiflexors - maximum }\end{array}$ & 1 & 65 & Mean Difference (IV, Fixed, 95\% CI) & $0.43[-1.62,2.48]$ \\
$\begin{array}{c}\text { isometric voluntary contraction } \\
4 \text { Muscle strength ankle } \\
\text { dorsiflexors - dynamic strength }\end{array}$ & 1 & 65 & Mean Difference (IV, Fixed, 95\% CI) & $-0.44[-1.77,0.89]$ \\
\hline
\end{tabular}

Comparison 3. Aerobic exercise and strength training in mitochondrial myopathy

\begin{tabular}{lcccc} 
Outcome or subgroup title & $\begin{array}{c}\text { No. of } \\
\text { studies }\end{array}$ & $\begin{array}{c}\text { No. of } \\
\text { participants }\end{array}$ & Statistical method & Effect size \\
\hline $\begin{array}{c}1 \text { Muscle strength shoulder press } \\
- \text { maximum dynamic isotonic } \\
\text { voluntary contraction }\end{array}$ & 1 & 18 & Mean Difference (IV, Fixed, 95\% CI) & $-3.00[-14.71,4.71]$ \\
$2 \begin{array}{l}\text { Muscle strength butterfly - } \\
\text { maximum dynamic isotonic } \\
\text { voluntary contraction }\end{array}$ & 1 & 18 & Mean Difference (IV, Fixed, 95\% CI) & $6.4[-2.89,15.69]$ \\
$\begin{array}{l}3 \text { Muscle strength bicep curls - } \\
\text { maximum isotonic dynamic } \\
\text { voluntary contraction }\end{array}$ & 1 & 18 & Mean Difference (IV, Fixed, 95\% CI) & $7.3[-2.91,17.51]$ \\
\hline
\end{tabular}




\begin{tabular}{lcccc}
$\begin{array}{c}4 \text { Work capacity - mean time until } \\
\text { exhaustion in cycle test }\end{array}$ & 1 & 18 & Mean Difference (IV, Fixed, 95\% CI) & 23.7 [2.63, 44.77] \\
$\begin{array}{c}5 \text { Work capacity- mean distance } \\
\text { until exhaustion in cycle test }\end{array}$ & 1 & 18 & Mean Difference (IV, Fixed, 95\% CI) & $9.70[1.51,17.89]$ \\
$\begin{array}{l}6 \text { Work capacity - mean distance } \\
\quad \text { walked until exhaustion in }\end{array}$ & 1 & 18 & Mean Difference (IV, Fixed, 95\% CI) & $78.0[-144.86,300$. \\
$\quad$ shuttle walking test & 1 & 18 & Mean Difference (IV, Fixed, 95\% CI) & $86]$ \\
$\begin{array}{l}7 \text { Quality of life } \\
8 \text { Myoglobin }\end{array}$ & 1 & 30 & Mean Difference (IV, Fixed, 95\% CI) & $-21.0[-48.35,6.35]$ \\
\hline
\end{tabular}

\section{ADDITIONAL TABLES}

Table 1. Quality of diagnostic criteria and training programme

\begin{tabular}{|c|c|c|c|c|c|c|c|c|}
\hline Study & Diagnosis & $\begin{array}{l}\text { Type of ex- } \\
\text { ercise }\end{array}$ & Intensity & Frequency & $\begin{array}{l}\text { Duration of } \\
\text { session }\end{array}$ & $\begin{array}{l}\text { Duration of } \\
\text { programme }\end{array}$ & $\begin{array}{l}\text { Muscle } \\
\text { groups }\end{array}$ & Supervision \\
\hline $\begin{array}{l}\text { Lindeman } \\
1995\end{array}$ & $\begin{array}{l}36 \text { adults } \\
\text { with my- } \\
\text { otonic dys- } \\
\text { trophy; } \\
34 \text { classical } \\
\text { adult type, } 2 \\
\text { congen- } \\
\text { ital form, di- } \\
\text { agnosis not } \\
\text { verified }\end{array}$ & $\begin{array}{l}\text { Dynamic } \\
\text { with weights }\end{array}$ & $\begin{array}{l}\text { Individ- } \\
\text { ualised pro- } \\
\text { gressive } \\
\text { overload, } 3 \\
\text { sets from } 25 \\
\text { repetitions } \\
\text { at } 60 \% \text { of } \\
1 \mathrm{RM} \text {, via } 15 \\
\text { repetitions } \\
\text { at } 70 \% \text {, } \\
\text { to } 10 \text { repeti- } \\
\text { tions at } 80 \%\end{array}$ & $\begin{array}{l}3 \text { times/ } \\
\text { week }\end{array}$ & $\begin{array}{l}\text { Within } 30 \\
\text { minutes }\end{array}$ & 24 weeks & $\begin{array}{l}\text { Knee exten- } \\
\text { sors } \\
\text { and flexors, } \\
\text { hip exten- } \\
\text { sors and ab- } \\
\text { ductors }\end{array}$ & $\begin{array}{l}\text { Super- } \\
\text { vised home } \\
\text { training pro- } \\
\text { gramme }\end{array}$ \\
\hline Scores & C & A & A & A & A & A & $\mathrm{C}$ & A \\
\hline $\begin{array}{l}\text { van der Kooi } \\
2004\end{array}$ & $\begin{array}{l}65 \\
\text { genetically } \\
\text { confirmed } \\
\text { adults with } \\
\text { facioscapu- } \\
\text { lohumeral } \\
\text { muscular } \\
\text { dystrophy }\end{array}$ & $\begin{array}{l}\text { Dynamic } \\
\text { and isomet- } \\
\text { ric with } \\
\text { weights }\end{array}$ & $\begin{array}{l}\text { Individ- } \\
\text { ualised pro- } \\
\text { gressive } \\
\text { overload, } 2 \\
\text { sets dynamic } \\
\text { from } 10 \text { rep- } \\
\text { etitions at } \\
10 \mathrm{RM} \text {, via } \\
8 \text { repetitions } \\
\text { at } 8 \mathrm{RM} \text {, to } \\
5 \text { repetitions } \\
\text { at } 5 \mathrm{RM} \text {, and } \\
30 \text { s iso- } \\
\text { metric with } \\
\text { same weight }\end{array}$ & $\begin{array}{l}3 \text { times/ } \\
\text { week }\end{array}$ & $\begin{array}{l}\text { Within } 30 \\
\text { minutes }\end{array}$ & 52 weeks & $\begin{array}{l}\text { El- } \\
\text { bow flexors, } \\
\text { ankle dorsi- } \\
\text { flexors }\end{array}$ & $\begin{array}{l}\text { Super- } \\
\text { vised home } \\
\text { training pro- } \\
\text { gramme }\end{array}$ \\
\hline Scores & A & A & A & A & A & A & $\mathrm{C}$ & A \\
\hline
\end{tabular}


Table 1. Quality of diagnostic criteria and training programme (Continued)

\begin{tabular}{|c|c|c|c|c|c|c|c|c|}
\hline $\begin{array}{l}\text { Cejudo } \\
2005\end{array}$ & $\begin{array}{l}20 \text { partic- } \\
\text { ipants diag- } \\
\text { nosed with } \\
\text { mitochon- } \\
\text { drial myopa- } \\
\text { thy on the } \\
\text { basis of clin- } \\
\text { ical, familial } \\
\text { and muscle } \\
\text { biopsy data }\end{array}$ & $\begin{array}{l}\text { Endurance } \\
\text { bicycle } \\
\text { training, dy- } \\
\text { namic } \\
\text { isotonic } \\
\text { with weights }\end{array}$ & $\begin{array}{l}\text { Aerobic } \\
\text { train- } \\
\text { ing: individ- } \\
\text { ualised work } \\
\text { rate, } 30 \text { - } \\
\text { minute } \\
\text { leg exercise } \\
\text { on an ergo } \\
\text { cycle, } 70 \% \\
\text { of the peak } \\
\text { work rate } \\
\text { Strength } \\
\text { train- } \\
\text { ing: one set } \\
\text { dynamic } \\
\text { and isotonic } \\
\text { of } \quad 10 \\
\text { to } 15 \text { repeti- } \\
\text { tions at } 50 \% \\
1 \text { RM load, } \\
\text { to } 2 \text { or } 3 \text { sets } \\
\text { Adjust- } \\
\text { ments } \\
\text { on workload } \\
\text { changed ev- } \\
\text { ery } 2 \text { weeks }\end{array}$ & $\begin{array}{l}3 \text { times/ } \\
\text { week }\end{array}$ & $\begin{array}{l}\text { Approxi- } \\
\text { mately } 60 \\
\text { minutes }\end{array}$ & 12 weeks & $\begin{array}{l}\text { Shoulder, } \\
\text { upper back, } \\
\text { arm, pec- } \\
\text { toralis ma- } \\
\text { jor, biceps } \\
\text { brachii and } \\
\text { brachialis } \\
\text { muscles }\end{array}$ & $\begin{array}{l}\text { Supervised } \\
\text { training pro- } \\
\text { gramme by } \\
\text { specialised } \\
\text { nurses and a } \\
\text { physiatrist } \\
\text { specialist in } \\
\text { a Rehabili- } \\
\text { tation Unit } \\
\text { on an outpa- } \\
\text { tient basis }\end{array}$ \\
\hline Scores & $\mathrm{C}$ & A & $\begin{array}{l}\text { A (strength } \\
\text { training) } \\
\text { A (aer- } \\
\text { obic exercise } \\
\text { training) }\end{array}$ & A & A & A & $\mathrm{C}$ & A \\
\hline
\end{tabular}

\section{WHAT'S NEW}

Last assessed as up-to-date: 13 July 2009.

\begin{tabular}{lll}
\hline Date & Event & Description \\
\hline 15 June 2011 & Amended & Additional acknowledgement added. \\
\hline
\end{tabular}




\section{H I S T O R Y}

Protocol first published: Issue 4, 2002

Review first published: Issue 1, 2005

\begin{tabular}{l|l|l}
\hline Date & Event & Description \\
\hline 20 July 2009 & New citation required and conclusions have changed & $\begin{array}{l}\text { Search updated to July 2009. Review updated to in- } \\
\text { clude a new study of people with mitochondrial my- } \\
\text { opathy (Cejudo 2005). The results and conclusions of } \\
\text { the review have been amended accordingly }\end{array}$ \\
\hline 2 July 2008 & Amended & Converted to new review format. \\
\hline 23 September 2004 & New citation required and conclusions have changed & Substantive amendment. \\
\hline
\end{tabular}

\section{CONTRIBUTIONS OFAUTHORS}

I Riphagen searched all databases. NBM Voet and EL van der Kooi identified and assessed potentially relevant studies, and extracted the data from included studies. NBM Voet prepared the final draft. ACH Geurts, EL van der Kooi and E Lindeman edited each draft and agreed the final text of the review.

\section{DECLARATIONS OF INTEREST}

One author (van der Kooi) carried out a randomised controlled trial on the effect of strength training and albuterol in facioscapulohumeral muscular dystrophy (van der Kooi 2004). The other (Lindeman) has co-ordinated a randomised controlled trial on the effects of strength training in myotonic dystrophy (Lindeman 1995).

\section{DIFFERENCES BETWEEN PROTOCOLANDREVIEW}

In this review we have excluded studies in which the the contralateral non-exercised side served as the control limb. Although there is evidence in the literature as to why these trials should not be included this was not pre-specified as an exclusion criteria in the protocol. Therefore, we will revise the protocol on the next update.

\section{NDEX TERMS Medical Subject Headings (MeSH)}

*Exercise; Mitochondrial Myopathies [*rehabilitation]; Muscular Dystrophy, Facioscapulohumeral [ ${ }^{*}$ rehabilitation]; Myotonic Dystrophy [*rehabilitation]; Physical Fitness; Randomized Controlled Trials as Topic 


\section{MeSH check words}

Humans

Copyright (C) 201 I The Cochrane Collaboration. Published by John Wiley \& Sons, Ltd. 